\title{
Theories of Reasoned Action and Planned Behavior as Models of Condom Use: A Meta- Analysis
}

Dolores Albarracín

University of Florida, dalbarracin@asc.upenn.edu

Blair T. Johnson

University of Connecticut, blair.t.johnson@uconn.edu

Martin Fishbein

Paige A. Muellerleile

Follow this and additional works at: https://opencommons.uconn.edu/chip_docs

Part of the Quantitative Psychology Commons

\section{Recommended Citation}

Albarracín, Dolores; Johnson, Blair T.; Fishbein, Martin; and Muellerleile, Paige A., "Theories of Reasoned Action and Planned Behavior as Models of Condom Use: A Meta-Analysis" (2001). CHIP Documents. 8.

https://opencommons.uconn.edu/chip_docs/8 


\title{
Theories of Reasoned Action and Planned Behavior as Models of Condom Use: A Meta-Analysis
}

\author{
Dolores Albarracín \\ University of Florida \\ Martin Fishbein \\ University of Pennsylvania
}

\author{
Blair T. Johnson \\ University of Connecticut \\ Paige A. Muellerleile \\ Syracuse University
}

\begin{abstract}
To examine how well the theories of reasoned action and planned behavior predict condom use, the authors synthesized 96 data sets $(N=22,594)$ containing associations between the models' key variables. Consistent with the theory of reasoned action's predictions, (a) condom use was related to intentions (weighted mean $r .=.45$ ), (b) intentions were based on attitudes $(r .=.58)$ and subjective norms $(r .=$ $.39)$, and (c) attitudes were associated with behavioral beliefs $(r .=.56)$ and norms were associated with normative beliefs $(r .=.46)$. Consistent with the theory of planned behavior's predictions, perceived behavioral control was related to condom use intentions $(r .=.45)$ and condom use $(r .=.25)$, but in contrast to the theory, it did not contribute significantly to condom use. The strength of these associations, however, was influenced by the consideration of past behavior. Implications of these results for HIV prevention efforts are discussed.
\end{abstract}

Because condom use can prevent infection with HIV and other STDs, health agencies have designed various interdisciplinary efforts, oriented by behavioral prediction models, to persuade people to use condoms consistently. For example, the health belief model (Becker, 1974; Rosenstock, 1974) posits in part that increasing perceptions of vulnerability to HIV infection should increase precautionary behavior. Yet a recent quantitative synthesis found that chronic perceived vulnerability to HIV infection in members of high-risk groups is insufficient to motivate protective actions (Gerrard, Gibbons, \& Bushman, 1996; but see Bryan, Aiken, \& West, 1996). The limited support for the perceived-risk hypothesis suggests a need for other behavioral models of HIVrisk-related behavior.

In the present article, we modeled condom use behavior on the basis of two general theories of behavior: (a) the theory of rea-

Dolores Albarracín, Department of Psychology, University of Florida; Blair T. Johnson, Department of Psychology, University of Connecticut; Martin Fishbein, the Annenberg School of Communication, University of Pennsylvania; Paige A. Muellerleile, Department of Psychology, Syracuse University.

This research was supported by National Institutes of Health Grants R03-MH58073, K01-MH01861, K21-MH01377, and R01-MH58563 and by a research fellowship from the Alexander von Humboldt Foundation to Blair T. Johnson.

We thank Darius Chan, William Fisher, Barbara Rye, Diane Morrison, James Westaby, Daniel Montaño, Danuta Kasprzyk, and Christopher Agnew for providing unpublished data that we incorporated in this study. We also thank Michael P. Carey and Kerry L. Marsh for their feedback on an earlier version of this article, Misty Marshall for assistance with data retrieval, and Ringo Ho for unusually detailed methodological comments.

Correspondence concerning this article should be addressed to Dolores Albarracín, Department of Psychology, University of Florida, Gainesville, Florida 32611. Electronic mail may be sent to albarrac@psych.ufl.edu. soned action (Ajzen \& Fishbein, 1977, 1980; Fishbein, 1980; Fishbein \& Ajzen, 1975) and (b) the theory of planned behavior (Ajzen, 1988, 1991; Ajzen \& Driver, 1991; Ajzen \& Madden, 1986; Schifter \& Ajzen, 1985). Given that these models have predicted a wide range of behaviors successfully (see reviews by Ajzen, 1991; Eagly \& Chaiken, 1993; Sheppard, Hartwick, \&. Warshaw, 1988) and have served as a basis for several HIV prevention efforts (e.g., Kamb, Dillon, Fishbein, Willis, \& Project RESPECT Study Group, 1996; Kamb et al., 1998), we expected that they would also be valuable to predict condom use (cf. Sheeran \& Orbell, 1998). The large number of studies that have now examined these models in relation to condom use (see Albarracín \& Fishbein, 1993) and the variability of the findings suggest that a quantitative synthesis of this literature would prove valuable. Therefore, the purpose of the present research was to evaluate the success of the theories of reasoned action and planned behavior as predictors of condom use across studies and to examine the plausibility of the relations postulated by these models. For that purpose, we conducted a meta-analysis on the data reported in 42 published and unpublished articles, unpublished theses, dissertations, and technical reports, which together comprised 96 data sets.

\section{Theories of Reasoned Action and Planned Behavior}

Beyond the circumscribed context of condom use, ${ }^{1}$ the theories of reasoned action and planned behavior are comprehensive theories of many behaviors that specify a limited number of psychological variables that can influence a behavior, namely (a) intention; (b) attitude toward the behavior; (c) subjective norm; (d)

\footnotetext{
${ }^{1}$ Consistent with the convention in this literature, condom use implies the male condom. To date, the female condom has received scant attention.
} 
perceived behavioral control; and (e) behavioral, normative and control beliefs (see Fishbein et al., 1992).

\section{The Theory of Reasoned Action}

Fishbein and Ajzen's (1975; Ajzen \& Fishbein, 1980) theory of reasoned action, which is illustrated in the top panel of Figure 1, asserts that one's intentions influence overt behavior. Formally,

$$
B \approx I \text {, }
$$

where the person's overt action $B$ (generally measured by selfreport in this domain) is a function of the intention $I$ or willingness to perform the behavior (e.g., "How likely is it that, in the next six months, you will [would] use a condom the next time you have vaginal sex with her?"; Centers for Disease Control [CDC], 1993a, p. 7). Thus, one is likely to use condoms if one intends to use them. Intentions, in turn, are influenced by the attitude toward performing the behavior and the subjective norm. Attitude is the degree to which one has a positive versus a negative evaluation of the behavior $^{2}$ and is typically measured by a set of bipolar semantic differential scales (e.g., unpleasant-pleasant, unwise-wise, badgood, unnecessary-necessary, uncomfortable-comfortable; CDC, 1993a, p. 8). The subjective norm is the perception that important others think that one should or should not perform the behavior in question and is typically measured by items such as "People who are important to me think I should use condoms" (see e.g., W. A. Fisher, Fisher, \& Rye, 1995). Formally,

$$
I \approx A_{B_{w_{1}}}+S N_{B_{w_{2}}},
$$

where $I$ is the intention to perform behavior $B, A_{B}$ is the attitude toward performing behavior $B, S N_{B}$ is the subjective norm concerning behavior $B$, and $w_{1}$ and $w_{2}$ are weights for $A_{B}$ and $S N_{B}$,
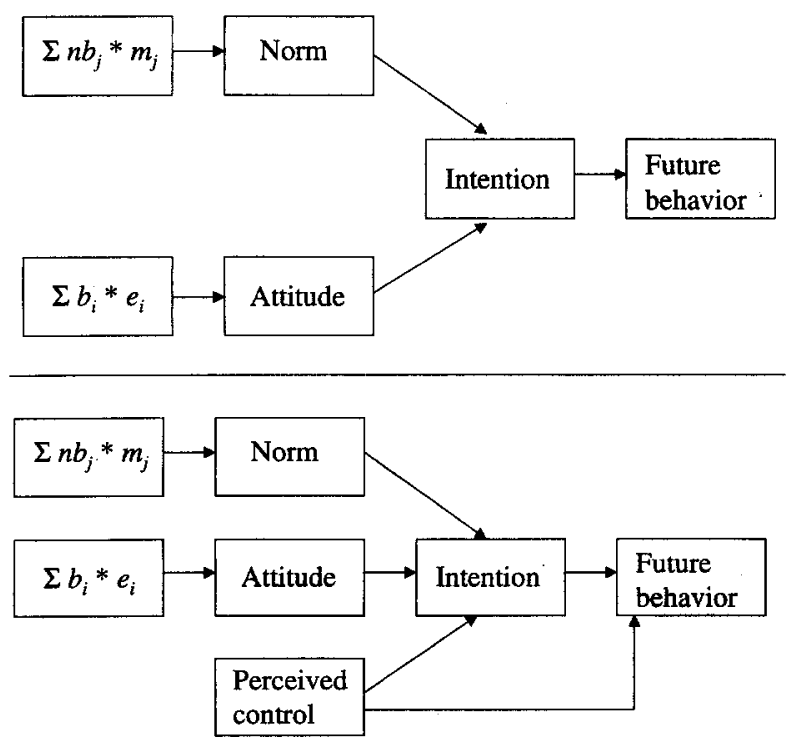

Figure 1. The theory of reasoned action (top) and the theory of planned behavior (bottom). $\sum n b_{j} * m_{j}=$ sum of Normative Beliefs $\times$ Motivation to Comply (indirect norm); $\Sigma b_{i} * e_{i}=$ sum of Beliefs $\times$ Evaluations (indirect attitude). respectively. In most studies, intention is driven by attitudes to a greater extent than by subjective norms (Eagly \& Chaiken, 1993).

The attitude toward the behavior is assumed to be a function of one's beliefs that performing the behavior in question will lead to various outcomes and the evaluative aspects of those beliefs (i.e., the evaluations of the outcomes). An expectancy-value estimate of attitude is obtained by weighting each salient belief that the outcome will occur $\left(b_{i}, i=1, \ldots, p\right)$ by the evaluative implications of that outcome $\left(e_{i}, i=1, \ldots, p\right)$. Thus, one is more likely to have a positive attitude toward using condoms if one believes that using a condom will lead to positive outcomes (e.g., "will make sex more fun") and prevent negative outcomes (e.g., "may help prevent STDs"). Formally,

$$
A_{B} \approx \sum_{i=1}^{p} b_{i} e_{i},
$$

where $A_{B}$ is the attitude toward performing behavior $B, b_{i}$ is the strength of the belief that performing behavior $B$ leads to outcome $i, e_{i}$ is the evaluation of outcome $i$, and $p$ is the number of salient outcomes. For convenience and because of the assumption that beliefs and evaluations underlie and determine attitudes (but see Albarracín \& Wyer, 2000; Fazio, 1990), the $\sum b_{i} e_{i}$ term is denoted indirect attitude. Behavioral or outcome beliefs are typically measured by bipolar probability statements linking the behavior to a set of outcomes ("My using condoms will prevent AIDS" with response options unlikely vs. likely; Chan, 1994, p. 84), whereas outcome evaluations are measured by means of bipolar evaluative items (e.g., "Preventing AIDS is ..." with response options bad vs. good; Chan, 1994; p. 83). This component of the model is critical when researchers are interested in modifying attitudes because it assumes that attitudes are based on beliefs (but see Bargh, Chaiken, Govender, \& Pratto, 1992; Fazio, 1990). However, outcome beliefs and evaluations are not a primary focus of this review as they do not contribute to actions in a direct fashion.

The subjective norm is also influenced by a set of salient beliefs about the normative prescriptions of specific referents, weighted by the motivation to comply with each of those referents. For example, a man may perceive social pressure to use condoms if he believes that his partner thinks that he should use condoms and he is motivated to comply with him or her. Thus,

$$
S N_{B} \approx \sum_{j=1}^{q} n b_{j} m_{j}
$$

where $S N_{B}$ is the subjective norm toward behavior $B, n b_{j}$ is the normative belief that referent $j$ thinks the respondent should or should not perform the behavior, $m_{j}$ is the motivation to comply with referent $j$, and $q$ is the number of referents. For convenience and because of the assumption that subjective norm is based on

\footnotetext{
${ }^{2}$ One important aspect of Fishbein and Ajzen's definition is that their attitude concerns the behavior, instead of the target or object. As these researchers showed, and as many other scholars have concurred (e.g., Eagly \& Chaiken, 1993), this definition of attitude is much more likely to be instrumental to behavior than a definition that centers around attitudes toward targets.
} 
normative beliefs and motivations to comply, the $\sum n b_{j} m_{j}$ term is denoted indirect subjective norm. Normative beliefs are typically measured by bipolar probability statements about the opinion of a specific referent (e.g., "Does your main partner think that you should or should not get him to use a condom every time you have vaginal sex with him?"; CDC, 1993a, p. 12), whereas motivations to comply are measured by means of unipolar items (e.g., "In general, I want to do what my partner wants me to do"; Chan, 1994, p. 83). The use of the $\sum n b_{j} m_{j}$ component to predict subjective norms assumes that subjective norms can be changed by changing the perceived positions of important referents or one's motivation to comply with those referents. According to the theory, this component contributes to actions only indirectly.

The predictive validity of the theory of reasoned action has been examined in numerous studies that have previously served as the literatures for at least three quantitative reviews. Ajzen and Fishbein (1973) reviewed 10 studies and reported a .63 average correlation for the prediction of behavior from intentions and a mean multiple correlation of .76 for the equation predicting intentions from both attitudes and norms. With similar objectives and larger samples of studies, Sheppard et al.'s (1988) and van den Putte's (1991) meta-analyses estimated correlations of .53 and .62 for the prediction of behavior and multiple correlations of .66 and .68, respectively, for the prediction of intentions. These research analyses were important in establishing the predictive validity of the theory of reasoned action as a comprehensive model of behavior. These previous syntheses, however, have not examined how useful the theory of reasoned action is to predict condom use, nor have they examined the overall structure of the model.

Because many researchers have used retrospective reports of past behavior as the criterion variable, it is generally difficult to decide the extent to which behavior results from or leads to intentions and attitudes (Bem, 1965; see also Osberg \& Shrauger, 1986). ${ }^{3}$ Moreover, when intention and behavior are measured at the same time, random error can inflate correlations artificially. Thus, we wished to determine whether, across the literature, intentions remain important predictors of future behavior after taking into account the influence of past behavior and, more generally, whether the theories' other posited associations remain plausible after including past behavior.

It is also important to note that although the theory of reasoned action assumes that behaviors are influenced only by intentions, other literature suggests that attitudes and past actions influence future behavior directly (Bargh, 1997; Bentler \& Speckart, 1979; Fazio, 1986). According to this view, one's current behavior may be habitual and triggered automatically by environmental stimuli. Such triggers are assumed to lead to a correlation between past behavior and future actions when the contexts are stable enough to act as conditional stimuli (see Ouellette \& Wood, 1998). Alternatively, it has also been argued that behavior may be elicited unintentionally when an evaluative representation is present, in which case attitudes could elicit condom use without further intentional elaboration (see, e.g., Bargh, 1997).

\section{Theory of Planned Behavior}

Although the theory of reasoned action typically provides an excellent account of volitional behaviors, Ajzen (1985; see also Ajzen \& Driver, 1991; Ajzen \& Madden, 1986) added the variable of perceived behavioral control in an effort to predict intentions and behaviors that are not completely under volitional control (see the bottom panel of Figure 1). Perceived behavioral control refers to one's perception of control over the behavior and is assumed to reflect the obstacles that one encountered in past behavioral performances. With the inclusion of this new factor, Ajzen's theory of planned behavior proposes that perceived behavioral control can influence behavior directly. Thus,

$$
B \approx I+P B C
$$

where $B$ is the behavior, $I$ is intention, and $P B C$ is perceived behavioral control. In addition to contributing to behavioral prediction, perceived behavioral control is assumed to influence a person's intention to use condoms (see Equation 6). That is, people with higher perceived control are more likely to form intentions to perform a particular action than those who perceive that they have little or no control. Formally,

$$
I \approx A_{B}+S N_{B}+P B C,
$$

where $I, A_{B}, S N_{B}$, and $P B C$ have been previously defined. Generally, perceived behavioral control is measured as an aggregate of perceptions that (a) one can or cannot perform the behavior if one wants to, (b) performing the behavior is or is not up to oneself, and (c) performing the behavior is easy or difficult (see Ajzen \& Madden, 1986). ${ }^{4}$

Although researchers have theorized about the importance of perceived behavioral control in this domain (see, e.g., Ajzen, 1991; Chan, 1994), the correlation between this variable and actual behavior has sometimes been disappointing. For example, Reinecke, Schmidt, \& Ajzen (1996) reported that after controlling for intention, the association between perceived behavioral control and condom use was $-.06(n s)$. One possible explanation for the low correlation is that, at least in this domain, perceived behavioral control may not capture actual control. In addition, Eagly and Chaiken (1993) questioned whether merely having control over a behavior should predict behavior. According to their perspective, control should only be relevant when people intend to perform the behavior in question. For example, they would argue that it requires little or no control over the use of condoms to not use them. Similarly, although they would agree that people are likely to develop positive intentions if they have a favorable attitude and perceive the behavior as controllable, they would argue that when people have negative attitudes and perceive normative pressure not to use condoms, control perceptions would be practically irrelevant to condom use intentions.

Another question raised about the perceived behavioral control construct is its relation to past behavior. Given that past behaviors

\footnotetext{
${ }^{3}$ Measurement factors can also produce inflated correlations. For example, because postdictive studies measure intentions and behavior at the same time, shared error variance and participants' hypothesis guessing can also account for higher correlations.

${ }^{4}$ Ajzen and Madden (1986) also proposed that perceived behavioral control depends on beliefs that there are obstacles to the behavior (i.e., control beliefs) and the perceived power of these obstacles to prevent the behavior from occurring. For reasons of space and because this component was not represented in the literature, we decided to omit a description of this aspect of the theory.
} 
are consequential for later behaviors (Ouellette \& Wood, 1998), it has been suggested that perceived behavioral control often impacts intentions and behaviors because perceptions of control are based on one's past behavior or because people attempt to appear consistent in their reports. To this extent, evidence of support for the inclusion of perceived control has to be considered in relation to past behavioral performances.

\section{The Present Meta-Analysis}

In the present meta-analysis, we integrated 96 data sets from 42 reports that tested the theory of reasoned action, the theory of planned behavior, or both. A study was eligible if it reported associations among several variables relevant to using condoms: behavior, intentions, attitudes, subjective norms, and perceived behavioral control. In order to assess path-analytic models, it was necessary to retrieve as many bivariate correlations among the variables of interest as possible. Therefore, studies were ineligible if they did not contain either the behavior or the intentional measure and if attitudes and subjective norms were not assessed either directly or indirectly. Thus, the studies in the database were those that were designed to test either the theory of reasoned action, the theory of planned behavior, or both. The resulting data sets were coded along the behavior and population dimensions of interest in this review. After testing the overall fit of the theories of reasoned action and planned behavior to the resulting meta-analytic correlation matrix, we performed similar analyses across populations and behavioral contexts to establish the generalizability of the models. In addition, we examined the cognitive and behavioral influences of past behavior and the adequacy of the theories after controlling for past behavior.

\section{Method}

\section{Sample of Studies}

References were first retrieved from PsycLIT, the Educational Resources Information Center, and the Social Science Index by means of selected keywords that included theory of reasoned action, theory of planned behavior, Fishbein, Ajzen, expectancy value, intention, attitude toward behavior, attitude toward act, subjective norm, social norm, and motivation to comply. Other reports were located by manual searches of articles in journals (i.e., Journal of Clinical and Consulting Psychology, Journal of Applied Social Psychology, Journal of Personality and Social Psychology, American Journal of Community Psychology, Health Psychotogy, American Journal of Public Health, and Journal of Sex Research) and from cross-references within obtained reports. In addition to our efforts to retrieve published material, we contacted 10 researchers in the field and requested unpublished material. As a result of this request, we received a number of unpublished data sets and theses that were also incorporated in this synthesis. Reports that were available by June 1996 were considered for inclusion in the sample of studies. A sample of 42 reports that contained at least one data set testing the theories of reasoned action and/or planned behavior resulted from using the following inclusion criteria.

1. Condom use behavior. We included only studies that directly involved condom use. Reports focusing on safer sex behaviors or other condom use-related behaviors (e.g., "buying condoms" or "carrying condoms") were excluded. This criterion served to make the sample of studies more homogeneous with regard to the target behavior.

2. Presence of a measure of condom use behavior or intention. Eligible studies had a measure of either intention or behavior or both. Composite measures of either intention or behavior were accepted only when they concerned alternative condom use behaviors (e.g., the average of intentions to use condoms with occasional and steady partners). If composite measures included factors other than condom use (e.g., average of using a condom and engaging in a conversation about sexual history), the study was excluded.

3. Presence of measures of both attitudinal and normative factors. Eligible studies measured both attitudinal (i.e., either direct, or indirect, belief-based measure of attitudes) and normative factors (i.e., either direct, or indirect, belief-based measure of norms).

4. Presence of measure of perceived behavioral control. Eligible studies testing the theory of planned behavior also included a measure of perceived behavioral control. We considered that a study measured perceived behavioral control if it measured the extent to which (a) participants can use condoms if they want to do so, (b) using condoms is up to them, and/or (c) using condoms is easy or difficult.

5. Presence of appropriate statistics. The report had to include the associations between at least two of the cognitive and behavioral variables listed in the first four criteria. Although studies did not always report complete correlation matrices, they were included if they reported the correlations or regression coefficients among the factors that pertain to the relations in the theories of reasoned action and planned behavior (e.g., correlations of intentions with attitudes and norms). In some cases, these associations were obtained by contacting the authors of the studies.

\section{Data Coding and Retrieval}

We first coded each study along several dimensions that described the behavior and the population of interest. Behavioral factors included (a) type of sex (vaginal, nonvaginal) and (b) type of partner (steady or main partner, casual or other partner). Population factors included (c) mean age of sample, estimated when necessary; (d) percentage of males in each sample; and (e) risk level (higher risk, including men who have sex with men, clients of STD clinics, injecting drug users, female sex partners of injecting drug users, sex workers, and multiple-partnered heterosexuals; lower risk, including samples other than those listed for higher risk and samples for which the authors provided no information; see CDC, 1996, for similar epidemiological classifications).

We retrieved from the studies correlations involving future behavior, intentions, direct attitudes, direct norms, indirect attitudes, indirect norms, and past behavior. In order to study the generalizability of the models across behaviors and populations, we divided data sets on this basis whenever it was possible. Specifically, we retrieved statistics that pertained to different behaviors (vaginal or nonvaginal sex, steady or occasional sex partners) and separated statistics for populations that differed on dimensions of gender, age, and HIV risk.

We made some decisions to ensure accurate retrieval of the data. If a variable was measured by means of multiple operations and the correlations for the alternate measures were high, we calculated the average of the relevant coefficients. Retrieval of coefficients was conducted by two coders working independently, who checked the obtained statistics iteratively. Occasional disagreements were resolved by consultation with a third coder. Following these rules, 24 studies provided 1 data set, 9 studies provided 2, 2 studies provided 4,1 study provided 6,2 studies provided 8 , and 2 studies provided 12 data sets. Out of the 96 samples or data sets, the majority (64\%) were completely independent (e.g., participants in one sample did not appear in any other sample), some (10\%) pertained to samples that we labeled nearly independent (e.g., $6 \%$ of the participants in one data set also appeared in another data set), and the remainder (26\%) pertained to samples that we labeled highly dependent (i.e., the majority of the participants in one data set also appeared in another data set). 


\section{Data Analysis}

We synthesized the theoretical relations of interest with statistical methods analogous to those used in traditional studies. Tests of the theory of reasoned action and the theory of planned behavior require simple correlations in order to examine (a) the magnitude of the intention-behavior relation (see, e.g., W. A. Fisher et al., 1995), (b) the magnitude of the relation between attitudes and $\sum b_{i} e_{i}$ (e.g., Ajzen \& Fishbein, 1980), and (c) the magnitude of the relation between norms and $\Sigma n b_{j} m_{j}$ (e.g., Albarracín, Fishbein, \& Middlestadt, 1998; Fishbein et al., 1992). Thus, reported correlations were retrieved or were derived from reports of multiple regression coefficients when the correlations among predictors were also reported. In order to identify the relative contribution of attitudes, norms, and perceived behavioral control (see Equations 2 and 5), it was necessary to regress intentions on attitudes, norms, and perceived behavioral control (see, e.g., Fisher et al., 1995). Even when regression coefficients could not be used to retrieve correlations, they were used to calculate average regression weights as reported in the studies. Finally, path-analytic procedures were adequate to examine all of these theoretical equations simultaneously (see, e.g., Reinecke et al., 1996). Beta weights were thus estimated by fitting models to the obtained correlation matrix.

Results

\section{Description of Studies}

As central tendencies indicated in Table 1 show, the data sets were all from relatively recent years, sampled populations that were relatively young, examined females and males in roughly equal proportions, and often had a higher level of risk for HIV infection. The data sets specified whether condom use pertained to

Table 1

Descriptive Statistics of the Studies

\begin{tabular}{lc}
\hline \multicolumn{1}{c}{ Variable } & Value \\
\hline Median year of report (based on 96 studies) & $93.56(3.53)$ \\
Location of study & \\
North America & $72(75 \%)$ \\
Caribbean Islands & $2(2 \%)$ \\
South America & $2(2 \%)$ \\
Europe & $9(9 \%)$ \\
Africa & $2(2 \%)$ \\
Australia & $9(9 \%)$ \\
Unidentified & $5(5 \%)$ \\
Median sample size (based on 96 studies) & 108.50 \\
Mean age of participants (based on 92 studies) & $26.75(9.63)$ \\
Mean \% female in sample (based on 96 studies) & $48.68(43.48)$ \\
Risk level & \\
Lower risk & $44(46 \%)$ \\
Higher risk & $52(54 \%)$ \\
Unclassified & $0(0 \%)$ \\
Type of sex & \\
Vaginal & $18(19 \%)$ \\
Nonvaginal & $21(22 \%)$ \\
Unspecified & $57(59 \%)$ \\
Type of partner & $24(26 \%)$ \\
Main & $25(26 \%)$ \\
Other & $47(49 \%)$ \\
Unspecified &
\end{tabular}

Note. Unless otherwise indicated, values in parentheses are standard deviations. vaginal or nonvaginal sex $53 \%$ of the time and often left the type of partner (main or occasional) unspecified. When information was available, measurement of behavior was most often accomplished in a prospective fashion. Table 2 lists the studies and samples within studies that composed the literature reviewed. In total, the studies sampled 22,594 participants of whom $49 \%$ were female; $46 \%$ of the participants had a relatively high level of risk for HIV infection.

\section{Tests of Hypotheses}

\section{Theories of Reasoned Action and Planned Behavior}

Weighted mean correlations. We followed Hedges and Olkin's (1985; see also Johnson, 1993; Johnson \& Eagly, 2000) meta-analytic fixed effects procedures to estimate weighted mean correlations $(r$.$) . In these procedures, correlations are converted$ using Fisher's $r$-to- $z$ transformations and weighted by $N-3$, the inverse of which is the variance of $z$, in analyses. For display and interpretative purposes, resulting weighted mean $z$ values are converted back to $r$ using Fisher's $z$-to- $r$ transformation. As expected, correlations obtained with these procedures were all at least moderate in size (Cohen, 1988; see Table 3). Of particular note, intentions correlated more highly with future condom use $(r .=$ .45) than did perceived behavioral control $(r .=.25, p<.0001$ for contrast), and attitudes correlated more strongly with intentions ( $r$. $=.58)$ than did either subjective norm $(r .=.39, p<.0001$ for contrast) or perceived behavioral control $(r .=.45, p<.0001$ for contrast). Indirect attitude (i.e., $\Sigma b_{i} e_{i}$ ) was highly correlated with attitude $(r .=.56)$, as was indirect subjective norm (i.e., $\left.\sum n b_{j} m j_{i}\right)$ with subjective norm $(r .=.46)$.

Weighted path analysis. The weighted correlations provided an $8 \times 8$ correlation matrix. We inserted unities in the diagonal. As other researchers have done (e.g., Premack \& Hunter, 1988; see Shadish, 1996; Viewesvaran \& Ones, 1995), we submitted this aggregated matrix to linear structural techniques, which are useful to obtain path coefficients and goodness-of-fit statistics. For these models, we assumed the smallest number of participants who provided the observations for any one of the correlations in the model (see Table 3); no substitution of missing data was performed. The predicted models were fitted using EQS (Bentler \& Wu, 1995) and estimated with unweighted least squares procedures.

We first performed path analysis based on the $7 \times 7$ matrix of mean correlations including future behavior, intentions, direct and indirect attitudes and norms, and perceived behavioral control. These path models excluded past behavior and were very similar to the theoretical models in Figure 1 with the exception that we allowed for intercorrelations (a) between subjective norms and attitudes and (b) between perceived behavioral control and attitudes and norms.

According to the goodness-of-fit statistics displayed in Table 4, the theories of reasoned action and planned behavior were plausible models to predict condom use. The path analysis diagrams appear in Figure 2. Path coefficients appear next to the solid unidirectional lines, and values of the squared multiple correlation appear above the right corner of the boxes for endogenous vari-

(text continues on page 154) 


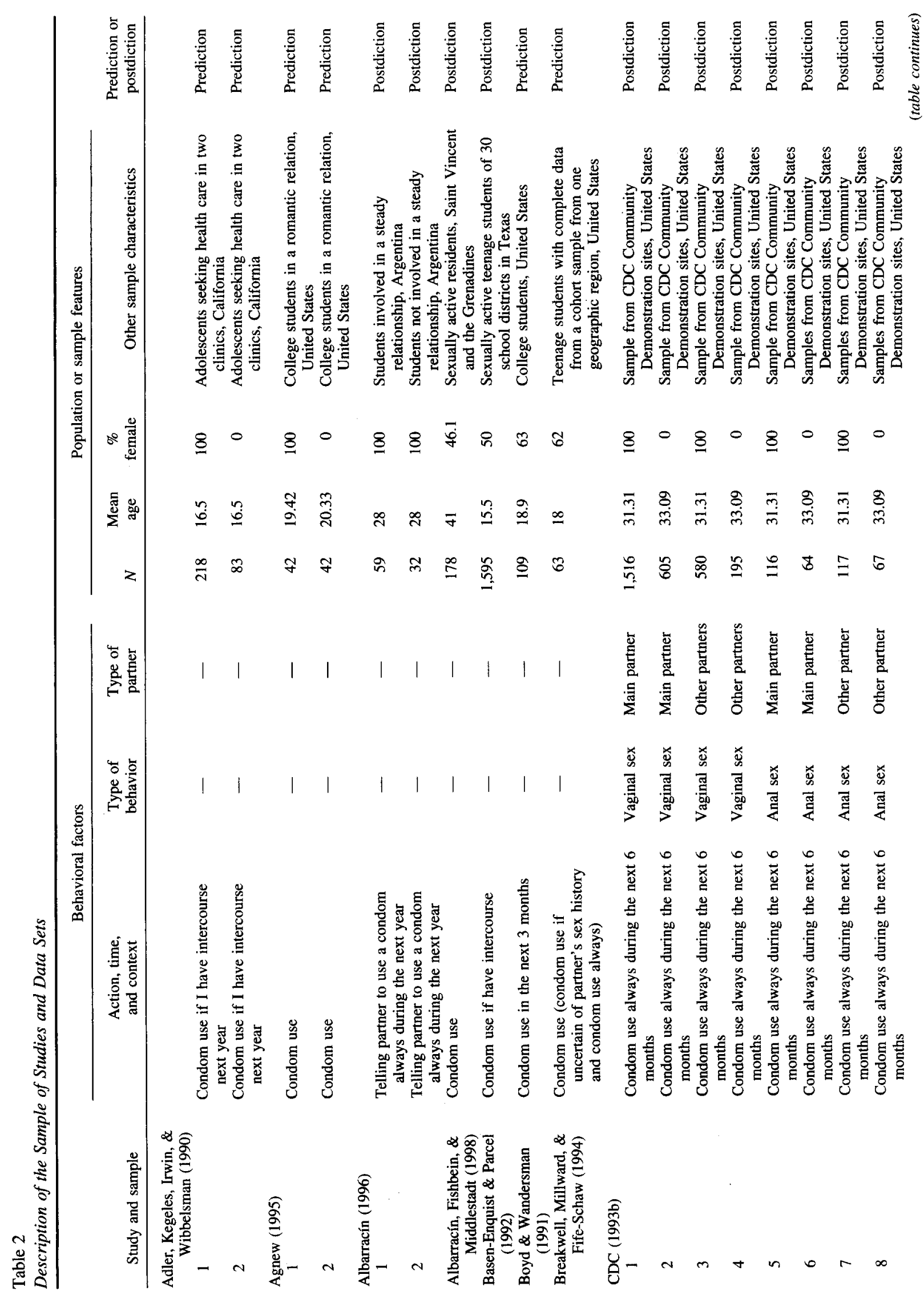




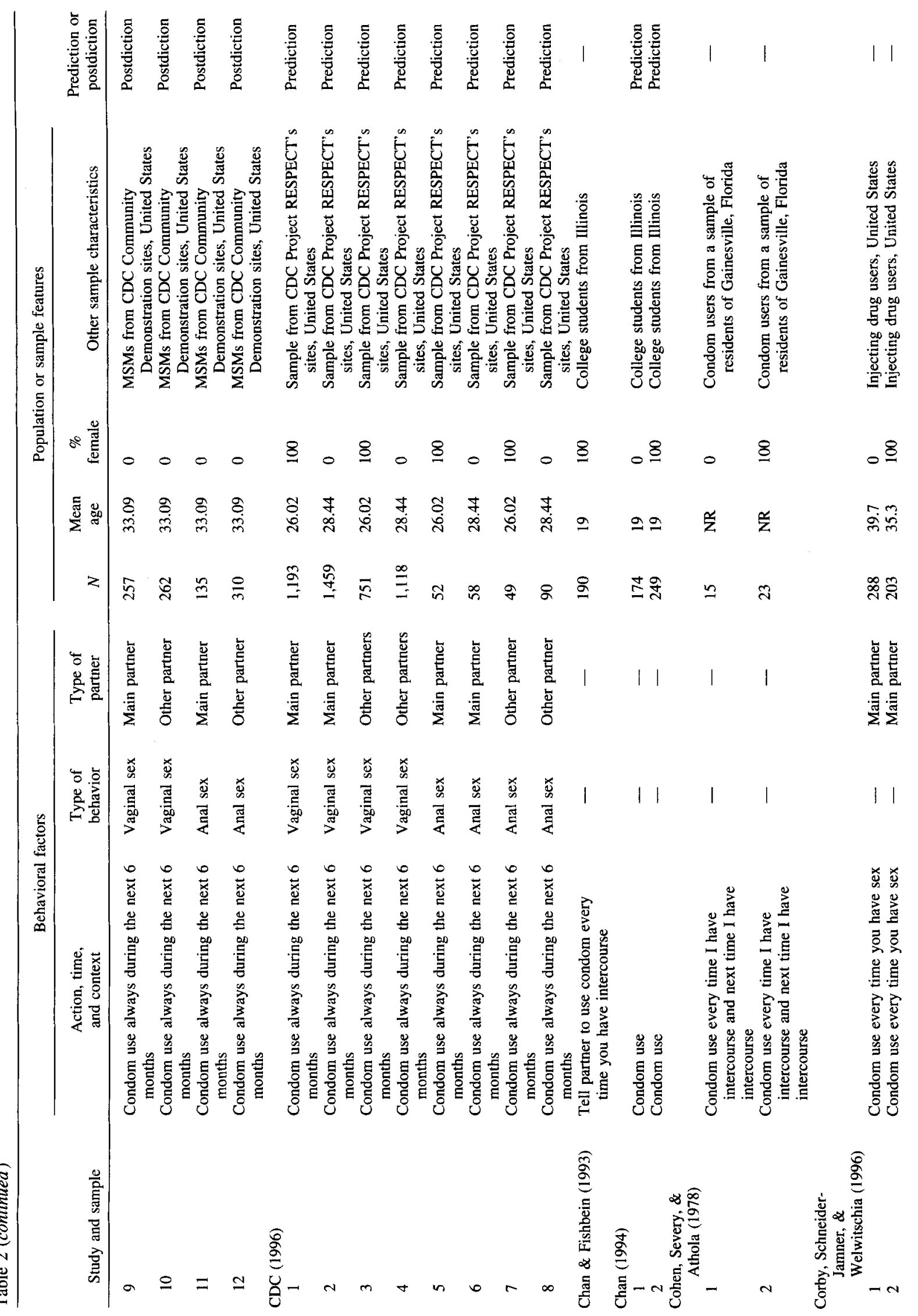



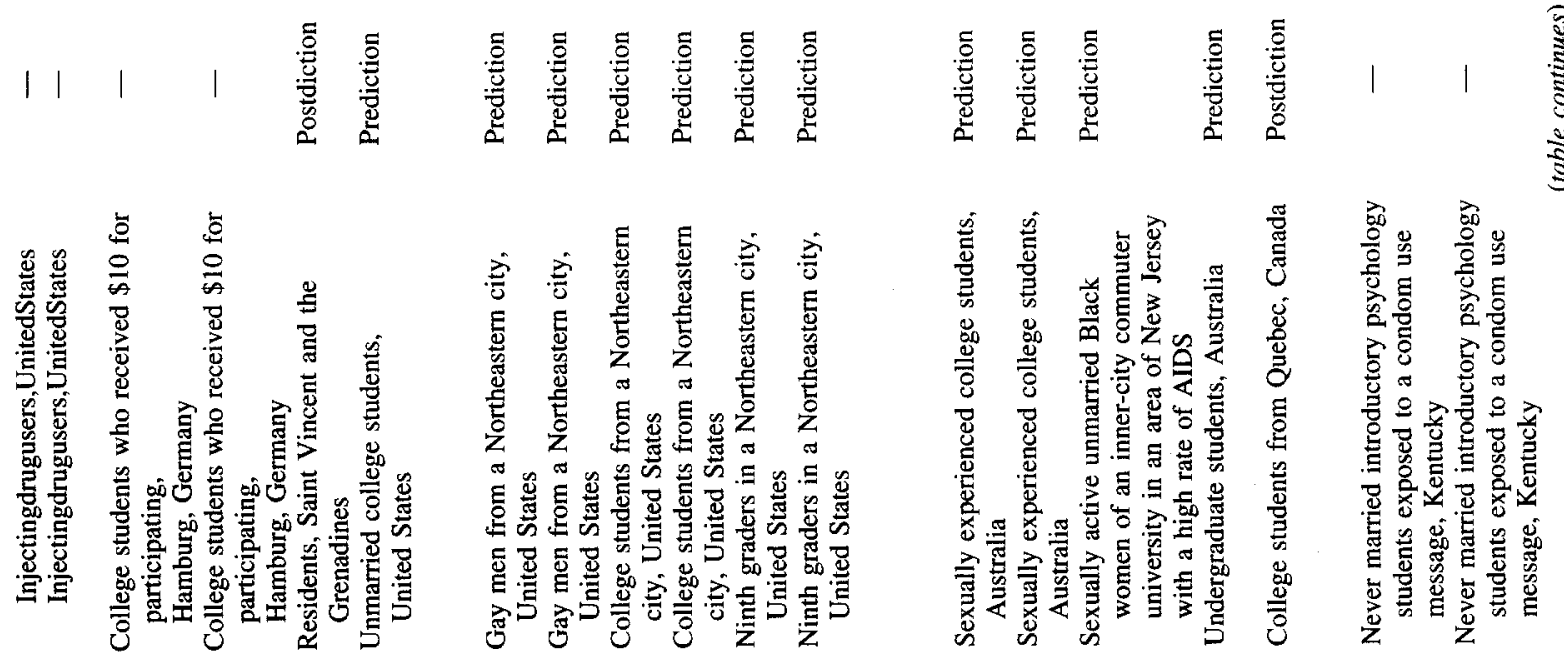

$\circ \underset{8}{8}$

- 8 萂

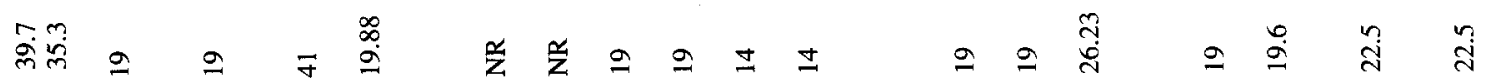

సัก

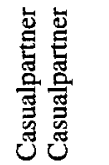

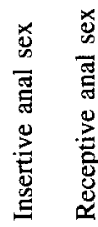

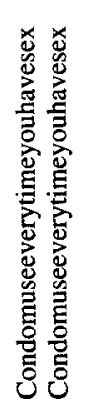

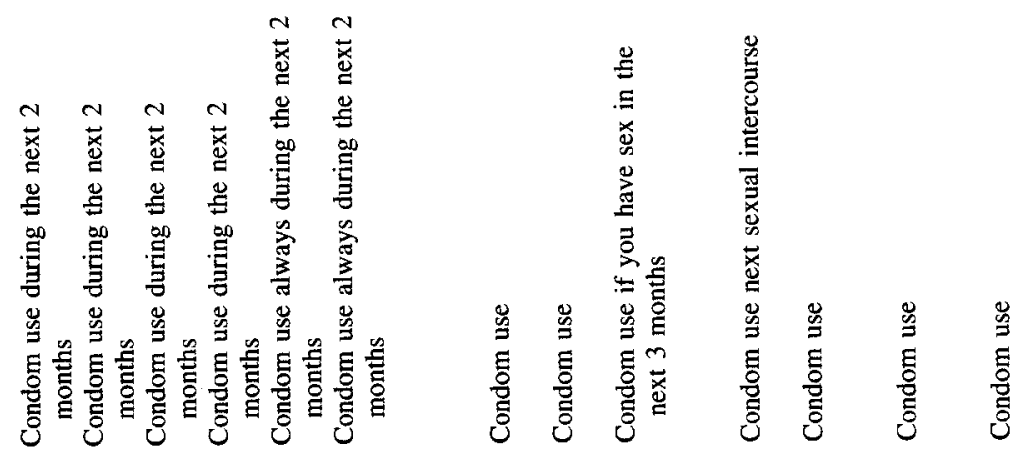

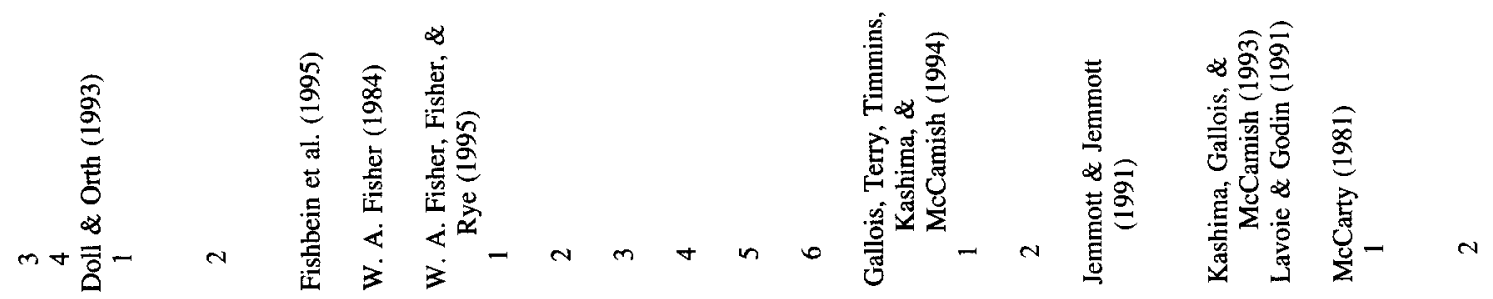




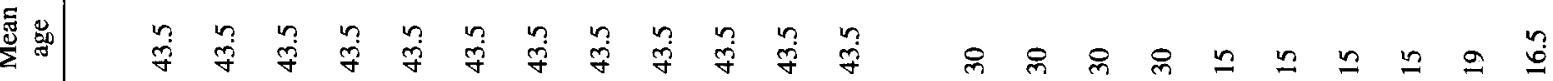

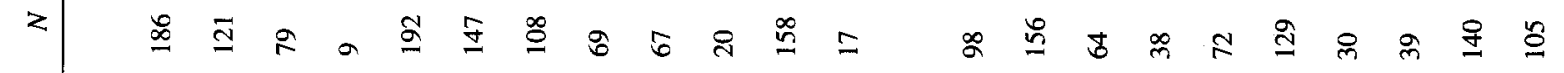

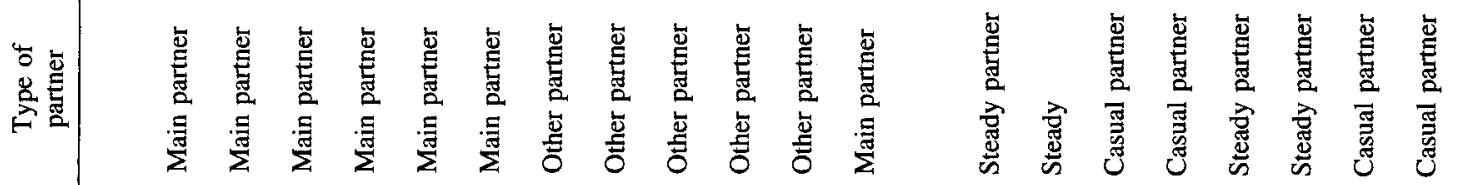

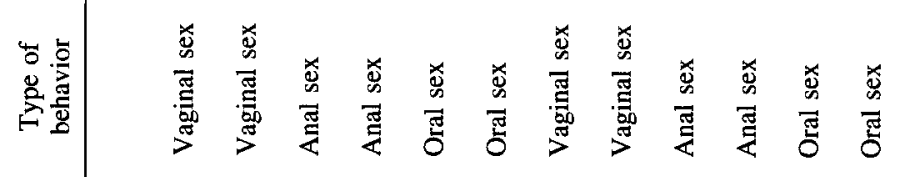

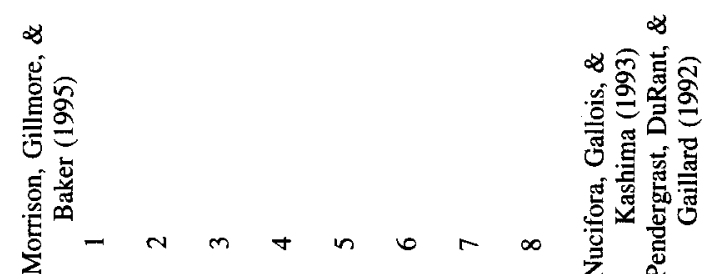


MODELS OF CONDOM USE

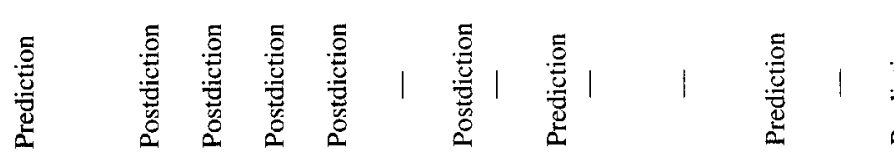

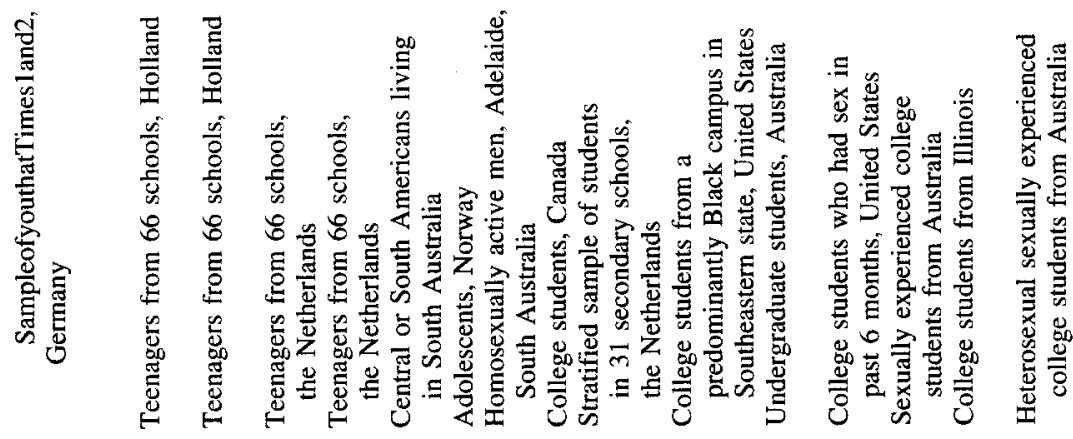

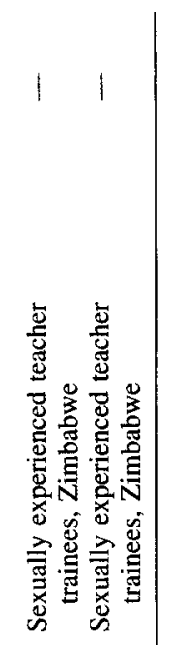

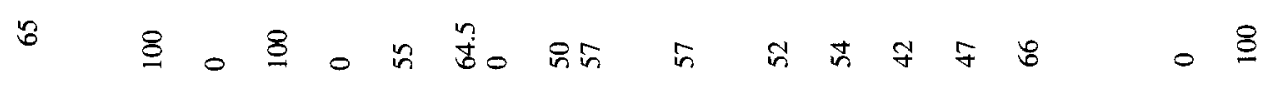

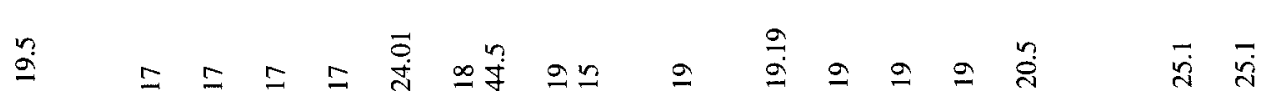

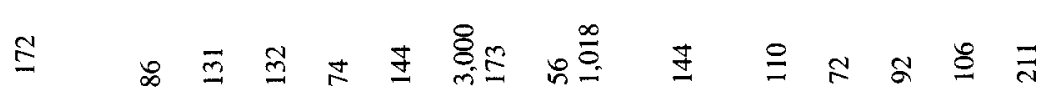

ฐ$$
\text { (1) }
$$

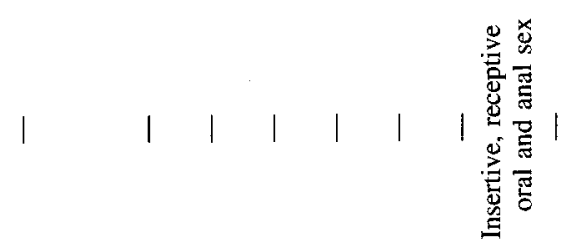
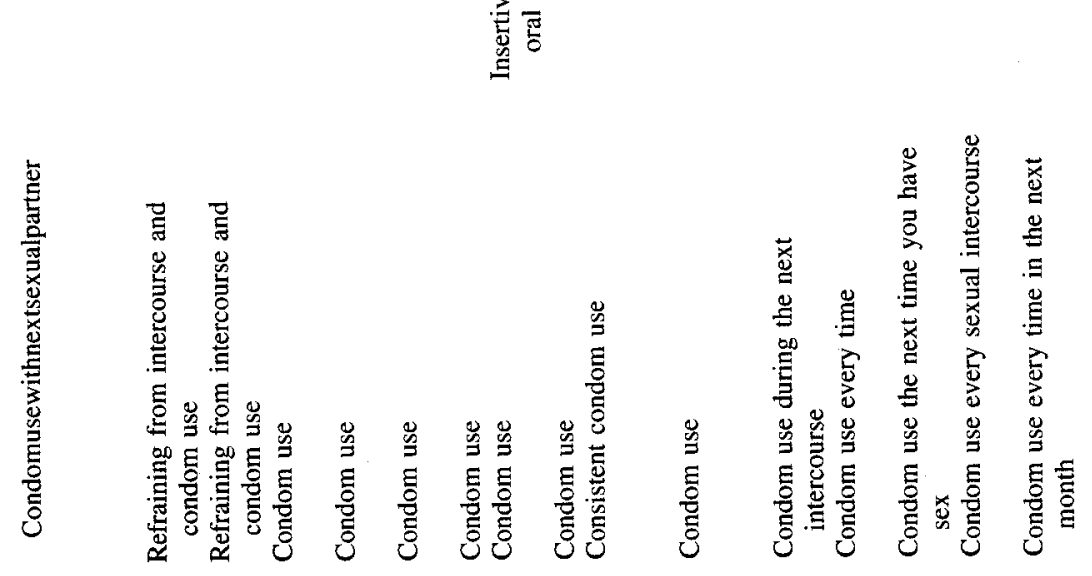


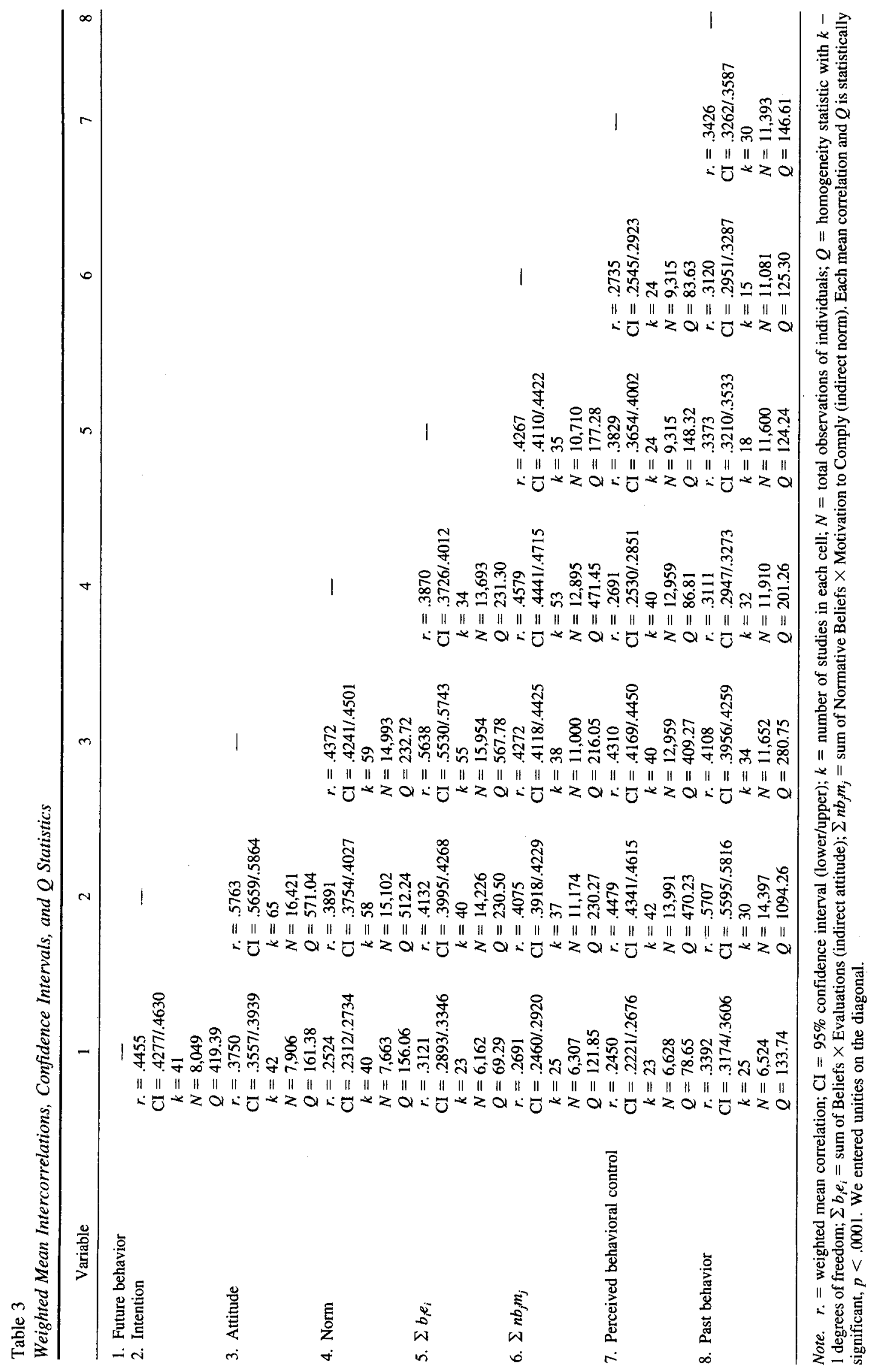


Table 4

Goodness-of-Fit Statistics for Models and Individual Paths Within the Models

\begin{tabular}{llllllllll} 
& \multicolumn{1}{c}{$\begin{array}{c}\text { Sample } \\
\text { size } \\
\text { information }\end{array}$} & & $\begin{array}{c}\text { Goodness of } \\
\text { fit }\end{array}$ & & & & & Tests of individual paths (for $\beta$ ) \\
Classification and theory & $k$ & $N$ & CFI & SRMR & $I \rightarrow B$ & $P B C \rightarrow B$ & $A \rightarrow I \quad S N \rightarrow I \quad P B C \rightarrow I \quad$ and $\Sigma n b^{*} m \rightarrow S N$ \\
\hline
\end{tabular}

Overall sample

Theory of reasoned action

Theory of planned behavior

\begin{tabular}{|c|c|c|c|c|c|c|c|c|c|}
\hline 23 & 6,162 & 1.00 & .06 & & & & & & \\
\hline 23 & 6,162 & .99 & .05 & .51 & $.05^{\mathrm{a}}$ & .47 & .21 & .20 & $.69, .55$ \\
\hline 21 & 5,943 & .99 & .06 & & & & & & \\
\hline 15 & 5,674 & .98 & .05 & .48 & $.04^{\mathrm{a}}$ & .53 & .17 & .18 & $.66, .51$ \\
\hline 9 & 3,325 & 1.00 & .07 & & & & & & \\
\hline 8 & 3,664 & 1.00 & .06 & .56 & .11 & .46 & .25 & .17 & $.68, .59$ \\
\hline 14 & 2,837 & .98 & .05 & & & & & & \\
\hline 14 & 3,510 & .98 & .05 & .42 & $-.02^{\mathrm{a}}$ & .49 & .14 & .26 & $.63, .45$ \\
\hline 8 & 5,005 & .99 & .06 & & & & & & \\
\hline 8 & 5,005 & .98 & .05 & .46 & $.05^{\mathrm{a}}$ & .52 & .15 & .22 & $.71, .47$ \\
\hline 9 & 721 & 1.00 & .07 & & & & & & \\
\hline 8 & 689 & 1.00 & .07 & .60 & $-.22^{\mathrm{a}}$ & .63 & $.18^{\mathrm{a}}$ & $.18^{\mathrm{a}}$ & $.73, .62$ \\
\hline 8 & 3,386 & 1.00 & .06 & & & & & & \\
\hline 8 & 3,386 & 1.00 & .05 & .53 & $.04^{2}$ & .56 & .17 & .18 & $.76, .53$ \\
\hline 7 & 2,288 & .96 & .05 & & & & & & \\
\hline 7 & 2,288 & .96 & .05 & .35 & $.04^{\mathrm{a}}$ & .46 & .14 & .27 & $.61, .43$ \\
\hline 10 & 2,479 & .98 & .07 & & & & & & \\
\hline 10 & 2,479 & .98 & .05 & .51 & $.02^{\mathrm{a}}$ & .44 & .17 & .29 & $.66, .54$ \\
\hline 10 & 3,419 & .99 & .07 & & & & & & \\
\hline 10 & 3,419 & .98 & .05 & .53 & $.04^{\mathrm{a}}$ & .42 & .21 & .27 & $.64, .54$ \\
\hline 6 & 63 & .96 & .12 & .44 & & .47 & .31 & & $.62, .51$ \\
\hline 0 & 0 & NA & NA & $\mathrm{NA}$ & NA & NA & NA & $\mathrm{NA}$ & NA, NA \\
\hline 15 & 5,674 & .99 & .06 & & & & & & \\
\hline 15 & 5,674 & .99 & .05 & .52 & $.03^{\mathrm{a}}$ & .48 & .22 & .20 & $.67, .56$ \\
\hline 21 & 5,943 & 1.00 & .06 & & & & & & \\
\hline 19 & 5,923 & .99 & .05 & .49 & $.01^{\mathrm{a}}$ & .52 & .16 & .22 & $.71, .48$ \\
\hline 2 & 219 & 1.00 & .11 & & & & & & \\
\hline 2 & 219 & 1.00 & .09 & .57 & $.25^{\mathrm{a}}$ & .27 & .41 & $.14^{\mathrm{a}}$ & $.61, .73$ \\
\hline
\end{tabular}

Matrix with no missing correlations (listwise)

Theory of reasoned action

Theory of planned behavior

Samples with statistically independent observations

Theory of reasoned action

Theory of planned behavior

Samples with statistically dependent observations

Theory of reasoned action

Theory of planned behavior

Vaginal sex

Theory of reasoned action

Theory of planned behavior

Nonvaginal sex

Theory of reasoned action

Theory of planned behavior

Steady partner

Theory of reasoned action

Theory of planned behavior

Casual partner

Theory of reasoned action

Theory of planned behavior

Samples with at least $60 \%$ females

Theory of reasoned action

Theory of planned behavior

Samples with at least $60 \%$ males

Theory of reasoned action

Theory of planned behavior

Samples with mean age less than 18 years

Theory of reasoned action

Theory of planned behavior

Samples with mean age at least 18 years

Theory of reasoned action

Theory of planned behavior

Higher HIV risk

Theory of reasoned action

Theory of planned behavior

Lower HIV risk

Theory of reasoned action

Theory of planned behavior

Note. Two goodness-of-fit indices were used following $\mathrm{Hu}$ and Bentler's (1998) suggestions for sensitivity to model specification under different distributions and sample sizes. The comparative fit index (CFI) is considered adequate when it exceeds .90 (Bentler \& Wu, 1995; Bollen, 1989). The standardized root mean residual (SRMR) represents good fit when it is equal to or less than .05 , marginal fit between .06 and .08 , and poor fit above .09 . $k=$ minimum number of studies in the matrix; $N=$ minimal sample size in analysis; $I=$ intention; $B=$ behavior; $P B C=$ perceived behavioral control; $A=$ attitude; $S N=$ subjective norm; $\Sigma b^{*} e=$ sum of Beliefs $\times$ Evaluations (indirect attitude); $\Sigma n b^{*} m=$ sum of Normative Beliefs $\times$ Motivation to Comply (indirect norm). The degrees of freedom were 15 and 21 for the theories of reasoned action and planned behavior, respectively. Testing moderators of individual paths was beyond the scope of this article.

${ }^{a}$ The path coefficient was not significant at $p<.01$. 

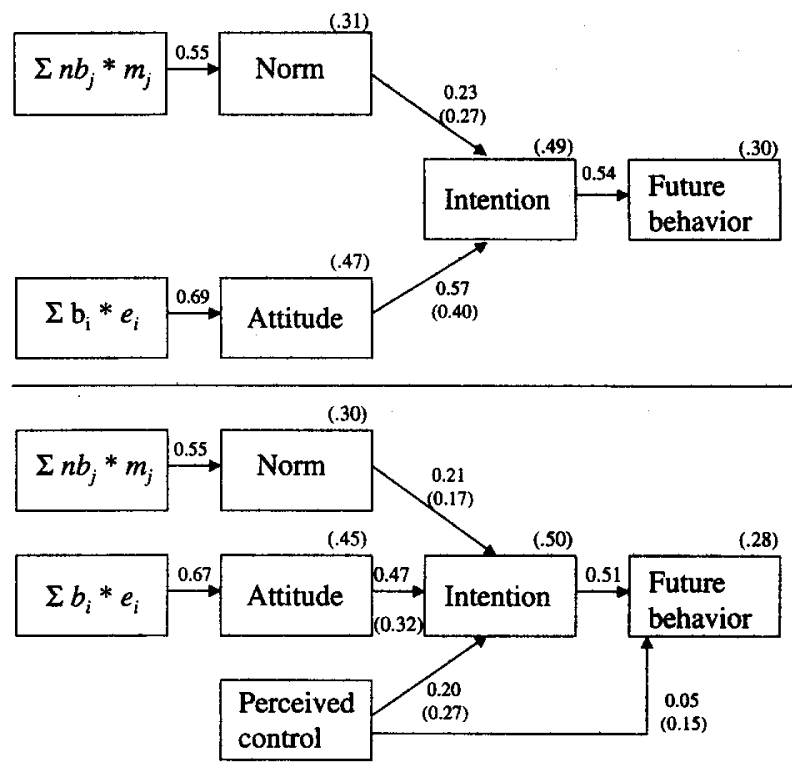

Figure 2. Path analysis for the theory of reasoned action (top) and the theory of planned behavior (bottom) with overall matrix of mean weighted correlations. Correlations between model components: (a) direct attitude and norm, .33; (b) indirect attitude and norm, .59; (c) perceived behavioral control and direct attitude, .21 ; (d) perceived behavioral control and direct norm, .11; (e) perceived behavioral control and indirect attitude, .41; and (f) perceived behavioral control and indirect norm, .31. $\Sigma n b_{j} * m_{j}=$ sum of Normative Beliefs $\times$ Motivation to Comply (indirect norm); $\Sigma b_{i}^{* * e_{i}}=$ sum of Beliefs $\times$ Evaluations (indirect attitude).

ables. ${ }^{5}$ To provide convergent evidence on the size of the path coefficients in these models, we also used the average beta weights obtained from multiple regression analyses reported in the studies. As the parenthetical values following the betas in Figure 2 show, these analyses were highly convergent. As implied by the theories and as shown in Figure 2, condom use is predicted from attitudes and norms, which are, in turn, influenced by the corresponding sets of salient beliefs. The influence of perceived behavioral control on intention was moderate $(\beta=0.20)$, and its direct impact on behavior was very small $(\beta=0.05){ }^{6}$

To examine the generality of these models across several important study dimensions, we produced several different matrices by focusing on specific subsets of the complete database and then retested the models in Figure 2 using the smallest sample size in each matrix. These values appear in Table 4 along with goodnessof-fit indices and a description of the beta weights obtained. First, to see if our path analytic findings were biased by the use of a weighted correlation matrix with an unequal number of data sets in each cell (see Shadish, 1996), we generated a matrix using listwise deletion procedures and fitted the models again; both the theories of reasoned action and planned behavior had a good fit (see Table 4). Second, we examined the models within the subset of studies that were statistically independent; once again, the models had an adequate fit. In addition, we examined the fit of the model across behavioral and population factors that varied across studies. Thus, we fitted the models to the correlation matrices for subsamples of (a) condom use for vaginal and nonvaginal sex, (b) condom use with steady and casual partners, (c) samples with greater propor- tions of females and samples with greater proportions of males, (d) samples with a mean age of less than 18 and samples with a mean age of 18 or more, and (e) samples at higher and lower HIV risk. Both the indices in Table 4 and the convergence in the implications of the model coefficients suggest that, except for the lack of support for a direct influence of perceived behavioral control on actual condom use, the structure of the theories was generally plausible across different behavioral contexts and populations. ${ }^{7}$

On the basis of the standardized root mean residual (SRMR) results, however, there were two samples for which the models did not fit well. The theory of reasoned action did not fit well when tested among teens, which may suggest that other processes that the models fail to represent may be responsible for condom use among this population. The other sample in which the models did not fit well according to the SRMR was the sample of studies with lower risk populations. However, because in these cases some of the cells in the correlation matrix contained so few studies $(k=2)$, we decided not to introduce post hoc modifications to the path model until more samples become available in the literature.

\section{The Role of Past Behavior in Reasoned Action and Planned Behavior}

We also examined the difference between using postdictive versus predictive measures of behavior. As can be seen in Table 3 , intentions correlated more strongly with past behavior than with future behavior (.57 vs. $.45, p<.001$ for contrast). Similarly, perceived behavioral control was more strongly associated with past behavior than with future behavior ( .34 vs. $.25, p<.001$ for contrast). This pattern of findings suggests that although intentions may influence future behavior, people's retrospective inferences about their past behavior can influence their intentions.

Given that past behavior may be used as information for intentions and perceived behavioral control, we again tested the theories of reasoned action and planned behavior with some adjustments that capitalized on the studies that assessed past behavior. Specifically, the new models were very similar to the ones in Figure 2,

\footnotetext{
${ }^{5}$ Because of correlated errors, the squared multiple correlations from different models cannot be used for comparisons.

${ }^{6}$ As discussed in the introduction, it is reasonable to expect perceived behavioral control to influence behaviors and intentions only when the valence of the behavior is subjectively positive. That is, $B=I+P B C+$ $I^{*} P B C$ and $I=A+S N+P B C+A^{*} P B C$. Although the products that are necessary to examine this hypothesis were not reported in the data sets we summarized, we requested the relevant data for the larger samples of Project RESPECT (CDC, 1996). Multiple regression analyses of males and females with main and occasional partners provided some support for this possibility. Thus, the interaction terms had a positive significant influence on behavior in three of the samples and on intentions in two of the samples.

${ }^{7}$ Of course, the finding that the models generalize across different behaviors and populations does not imply that the components in the model are identical. To examine the heterogeneity of the theories' associations, we calculated $Q$, which has an approximate chi-square distribution with $k$ -1 degrees of freedom, where $k$ is the number of studies (see Table 3). $Q$ provides an estimate of the amount of random variance that one can attempt to account for by considering moderators of a given relation. Supplementary analyses indicated that the strength of associations proposed generally varied as a function of type of sex, type of partner, age, gender, and risk level.
} 
except that past behavior was also introduced as a new exogenous variable and linked to future behavior, intentions, direct and indirect attitudes and norms, and perceived behavioral control. The smallest sample size for each matrix was used in analyses (see Table 3). The new models had an excellent fit: The comparative fit index (CFI) was .97 and the SRMR was .05 in each case. As shown in the path diagram in Figure 3, although past behavior exerted strong influences on attitudes, norms, and intentions, most associations predicted by the theory of reasoned action remained moderate or strong. The influence of subjective norms on intentions, however, became small when past behavior was introduced into the model. Similarly, after controlling for past behavior, the influence of perceived behavioral control on both intentions and actual condom use was very small.

\section{Direct Influence of Attitude on Behavior}

We also examined the possibility that attitudes can have direct influences on future behavior that are not mediated by the forma- tion of more elaborate intentions. Thus, we added a path linking these two variables to the model in the bottom half of Figure 3. As can be seen from Figure 4, the new solution was very similar (CFI $=.98$, SRMR $=.03$ ), except that the path from attitudes to behavior was very similar in size to the path linking intentions and behavior.

\section{Discussion}

Our review indicates that the theories of reasoned action and planned behavior are highly successful predictors of condom use. It thus complements Gerrard et al.'s (1996) conclusion that chronic perceptions of HIV risk are minimally linked to preventive behavior by pointing to other factors that do predict condom use. Thus, people are more likely to use condoms if they have previously formed the corresponding intentions. These intentions to use condoms appear to derive from attitudes, subjective norms, and perceived behavioral control. These attitudes and norms, in turn, appear to derive from outcome and normative beliefs. Neverthe-

\section{A}

0.37

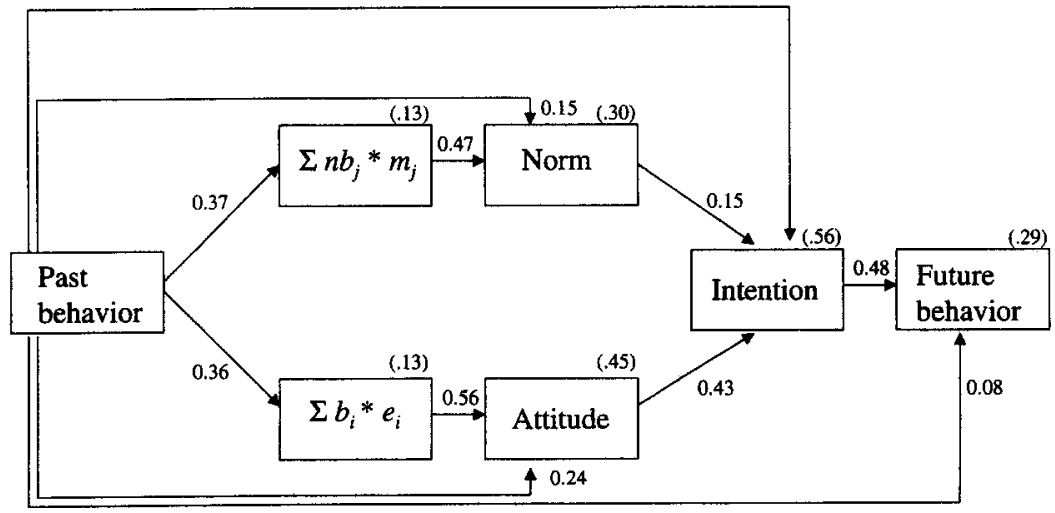

B 0.34

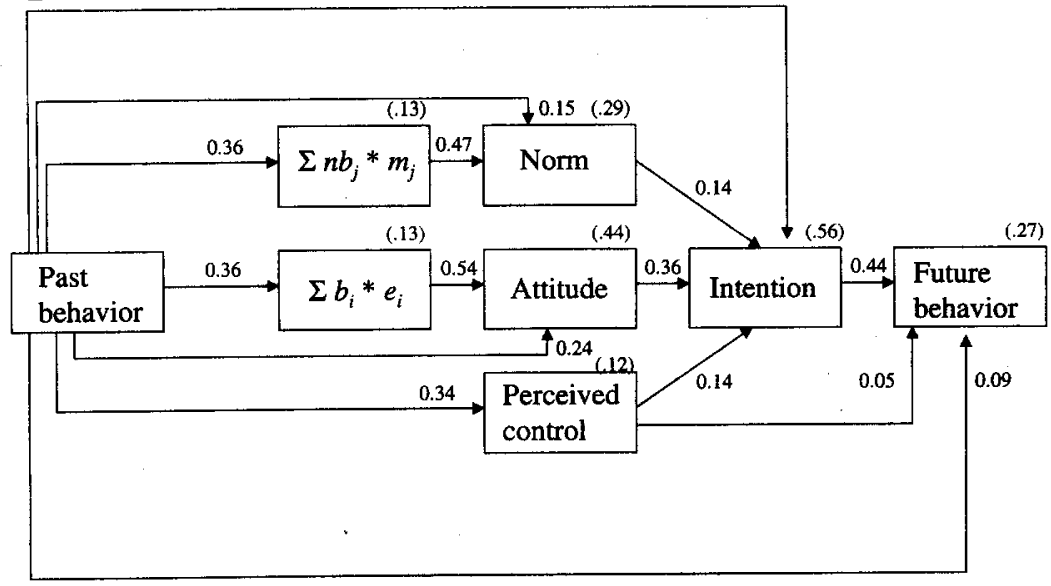

Figure 3. Path analyses for the theory of reasoned action (A) and the theory of planned behavior (B) including past behavior. Correlations between model components: (a) direct attitude and norm, .30; (b) indirect attitude and norm, .47; (c) perceived behavioral control and direct attitude, .19; (d) perceived behavioral control and direct norm, .10; (e) perceived behavioral control and indirect attitude, .32; and (f) perceived behavioral control and indirect norm, $.20 . \Sigma n b_{j} * m_{j}=$ sum of Normative Beliefs $\times$ Motivation to Comply (indirect norm); $\Sigma b_{i} * e_{i}=$ sum of Beliefs $\times$ Evaluations (indirect attitude). 


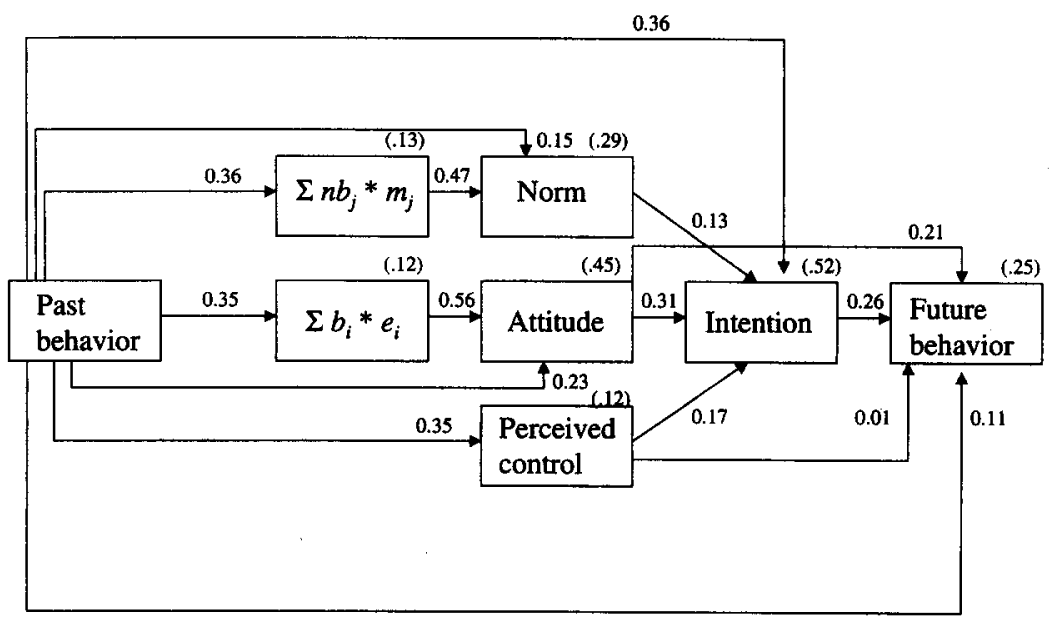

Figure 4. Path analyses for the theory of reasoned action and the theory of planned behavior including past behavior and direct influence of attitude on behavior. $\Sigma n b_{j} * m_{j}=$ sum of Normative Beliefs $\times$ Motivation to Comply (indirect norm); $\Sigma b_{i} * e_{i}=$ sum of Beliefs $\times$ Evaluations (indirect attitude).

less, whether behavior was assessed retrospectively or prospectively was an important moderator that influenced the magnitude of the associations between theoretically important variables.

\section{Determinants of Condom Use}

Our general predictions were that the theories of reasoned action and planned behavior would be plausible models of condom use. Thus, condom use was expected to be associated with intentions and perceived behavioral control; intentions were expected to correlate with attitudes, norms, and perceived behavioral control; and norms and attitudes were expected to correlate with the indirect, belief-based components.

\section{The Relation Between Intentions and Condom Use}

In this study, the weighted mean correlation between intention and future behavior was .45 , which is smaller than that reported by Sheppard et al. (1988) or by van den Putte (1991), .53 and .62, respectively. One possible reason why the relation is smaller is that respondents, and women in particular, may have less control over condom use than over behaviors typically examined in other domains (e.g., church attendance or voting). Another possible reason is that in the current investigation, we distinguished between studies that assessed behavior retrospectively and prospectively. Not surprising, we found that studies had somewhat larger intention-behavior associations when they assessed condom use retrospectively rather than prospectively (i.e., .57 vs. .45). This pattern of results is consistent with the notion that people base their intentions (and their attitudes) on their past behaviors (e.g., Bem, 1965; see also Albarracín \& Wyer, 2000). Alternatively, as M. Ross (1989) and Strack (1995) have suggested, people may try to appear consistent, and this is clearly easier to do when assessments are obtained at the same time than when intentions and behavior are assessed at different time periods. In addition, postdictive studies measuring behavior and cognitions at the same time should result in a greater percentage of shared error variance. Thus, by failing to distinguish between postdiction and prediction, both
Sheppard et al. (1988) and van den Putte (1991) may have overestimated the strength of the intention-behavior relationship.

\section{The Relation Between Perceived Behavioral Control and Condom Use}

Although the weighted mean correlation between behavior and perceived behavioral control in the current research was moderate $\left(r_{\bullet}=.24\right)$, the impact of this latter variable on behavior was very small after controlling for the influence of intention $(\beta=0.05)$. These results are consistent with data reported by Reinecke et al. (1996), in which bivariate correlations of perceived behavioral control and different behavioral outcomes ranged from .24 to .32 , but the same associations became negligible $(\beta=-0.06, n s$; Reinecke et al., 1996) after controlling for the influence of intentions. Nevertheless, the correlation between behavior and perceived behavioral control is greater when behavior is measured retrospectively and perceived behavioral control is measured concurrently $(r=.34)$. To this extent, the more one has performed the behavior in the past, the more likely it is that one will perceive control over that behavior (see Figure 3).

\section{Past Behavior and Attitudes as Direct Determinants of Condom Use}

This meta-analysis also provided evidence concerning two other variables that may have implications for condom use. For example, past behavior had very small direct influences on future behavior $(\beta=0.09)$. This finding is consistent with Ouellette and Wood's (1998) conclusion that unstable contexts such as the ones frequently involved in condom use prevent habituation or automatization of the behavior. In addition, attitudes appear to have direct influences on behavior, although they do not contribute over and above the impact of intentions. The finding that attitudes have direct influences on actual behavior has often been taken as support for the argument that attitude can activate behavior automatically (Bargh, Chen, \& Burrows, 1996; but see Ajzen \& Fishbein, 
in press). It is important to note, however, that measurement error in intention could also be responsible for this effect, particularly when attitudes and behavior are assessed at different points in time.

\section{Prediction of Intentions, Attitudes, and Norms}

In the current meta-analysis, the multiple correlation coefficient when regressing intentions on attitudes and norms was .70 (see Figure 2); this correlation is slightly larger than meta-analytic reports by Sheppard et al. (1988) and van den Putte (1991) and slightly lower than the .76 reported by Ajzen and Fishbein (1973).

The correlation between attitudes and indirect, belief-based attitudes was .56 , similar to the .53 found by van den Putte (1991). The weighted mean correlation between norms and indirect norms (i.e., $\sum n b_{j} m_{j}$ ) was .46 , slightly lower than the .53 found by van den Putte.

\section{Limitations of the Present Study}

Prior to concluding with the implications of the current study for HIV prevention efforts, there are several limitations of this study to discuss. These limitations concern the validity of condom use reports, potential effects of measurement unreliability, effect heterogeneity, and conclusions about directionality.

\section{Factors Related to Measures of Condom Use}

The current results assume that self-reported behaviors are accurate reflections of persons' actions. The high reliability of properly assessed self-reports in relation to sexual behavior has been established by the use of interpartner reports (Coates et al., 1986; Jaccard \& Wan-Choi, 1995; McLaws, Oldenbrug, Ross, \& Cooper, 1990) and by the study of the association between self-reported condom use and seroconversion (CDC, 1997; Winkelstein et al., 1987). Nevertheless, it is reasonable to expect that the accuracy of self-reports will vary as a function of the population and the behavior. For example, if groups have particularly high alcohol or drug consumption, reports among their members could be less reliable than reports by other persons. Similarly, reports could be more reliable for frequent or infrequent behaviors, depending on the standards people use to assess sexual events, or temporal factors, such as recency or primacy (for a review of such phenomena, see Wyer \& Srull, 1989). Given these possibilities, the extent and nature of this bias under different circumstances has to be determined empirically.

\section{Other Measures}

One can also expect some measures to be better than others. For example, although the literature to date has not yet presented the rationales for using some measures of perceived behavioral control over others, there are some indications that some measures may be better than others. For instance, the studies in this review included traditional measures of perceived behavioral control, but there are several alternative conceptualizations and operationalizations. This construct is sometimes conceptualized as self-efficacy (Bandura, 1977, 1986, 1989, 1992, 1997; Forsyth, Carey, \& Fuqua, 1997) and measured by statements about the likelihood of performing the behavior under constraining circumstances (e.g., "when he's been drinking or doing drugs," "when you've been drinking or doing drugs," "when he is sexually excited," "when you are sexually excited," "when he doesn't feel like using a condom"; CDC, 1993a, p. 13). In other instances, despite Bandura's (1986) explicit dismissal of this practice, perceived control has been measured as the trait variable locus of control (Rotter, 1954), which is a general attributional tendency to perceive events as either fortuitous or volitional (see, e.g., Fishbein et al., 1995). We anticipate that future research comparing the many and diverse measures of perceived behavioral control will provide some solutions to this problem.

\section{Effect Heterogeneity}

Of importance, the correlations we summarized have considerable variability across the 96 databases that provided effect sizes (see Table 3). This great heterogeneity indicates the presence of behavioral, personal, situational, or measurement ${ }^{8}$ factors that have the potential to increase some correlations and decrease others. These analyses, however, were beyond the objectives of the present article.

\section{Directionality}

Although the theories of reasoned action and planned behavior specify variables in a causal sequence, it is important to keep in mind that the present study provides empirical summaries of correlational associations. For example, one cannot rule out the possibility that beliefs about the consequences of using condoms can both influence and be the result of attitudes (cf. Albarracín \& Wyer, in press; Fazio, 1990; Herr, 1995; but see Fishbein \& Middlestadt, 1995). Future research using more complex longitudinal or experimental designs should prove more adequate to disentangle these possibilities.

\section{Implications for Interventions to Change HIV-Risk Behaviors}

To the extent that condom use can be predicted successfully, practitioners ought to be able to improve the efficacy of interventions for targeted communities and individuals. Although researchers have been successful in designing interventions that reduce the risk for HIV infection, the specific factors responsible for this success remain somewhat unclear, because any one intervention tends to include more than one element that theoretically may be related to risk reduction (Kalichman, Carey, \& Johnson, 1996; West \& Aiken, 1997). In contrast, the current research highlights specific factors that can increase condom use and would be likely to succeed from a preventive standpoint.

The theories of reasoned action and planned behavior have already inspired a number of preventive efforts. Examples of these programs include the CDC's AIDS Community Demonstration Projects (CDC, 1996); Project RESPECT (CDC, 1997); preventive

\footnotetext{
${ }^{8}$ One example of a measurement factor that may be related to the magnitude of correlations in this literature is the reliability of the measures used to assess the variables in the theories of reasoned action and planned behavior. Unfortunately, studies only infrequently provided this information, making comparisons difficult.
} 
software for African Americans (Reis, Fishbein, \& Moore, 1996); theory-based interventions for women (West \& Aiken, 1997); counseling and testing interventions in Argentina (Glasman \& Albarracín, 1995); and information, motivation, and behavioral skills interventions for college students (J. D. Fisher, Fisher, Williams, \& Malloy, 1994), among others. For reviews of HIVintervention efforts, see J. D. Fisher and Fisher (1992); Kelly, Murphy, Sikkema, and Kalichman (1993); or meta-analyses by Kalichman et al. (1996) and Weinhardt, Carey, Johnson, and Bickham (1999).

Many of these interventions are attempts to modify people's beliefs about the outcomes of using condoms and to increase normative pressure to take preventive actions. Thus, attitudinal campaigns may tell teens' parents that "when you can't protect your kid anymore, condoms can" (Middlestadt, Fishbein, Albarracín, \& Helquist, 1995, p. 22). Similarly, counselors may counterargue beliefs about the negative outcomes of using condoms. For example, if a person reports that using a condom makes sex painful or uncomfortable, a counselor might probe for the reason why (CDC, 1993c). If the person says that condoms are too dry, the counselor can suggest extra lubricant. Alternatively, a counselor can discuss normative factors by asking a client to identify important people in his or her life and to imagine how each individual would respond to a condom use suggestion, with the objective of providing support for the client's intentions to use condoms (CDC, 1993c). Or the counselor may specifically state the following:

We have been talking a lot about condoms. As we have discussed, condoms are one of the best ways to prevent HIV. Because people are so concerned about HIV, condoms are becoming more accepted. Some people don't realize how much condom use is becoming a part of life in our community. For example, condoms are sold in a lot more places than they used to be, and the stores don't hide them in the back like they used to. Also condoms are talked about more on TV, in the movies and ... in music videos. (CDC, 1993c, pp. 38-39)

In addition to attempts to induce favorable attitudes and supporting social norms, interventions can also increase behavioral control among participants. For example, a counselor or facilitator may teach a client the steps necessary for condom use (e.g., having a condom available at all times, discussing condom use with the partner in a nonsexual situation) with the objective of conveying how condom use can become an event under the personal control of the client. Primary-level studies indicate that such interventions can increase perceptions of behavioral control (see Kelly et al., 1994).

Until now, however, whether to use an attitudinal, a normative, or a perceived control intervention has been suggested by baseline research or by the intuition of individual practitioners. Although appropriately conducted baseline research will always provide the most valid information for guiding the development of interventions, resources (e.g., time, money, personnel) often do not permit such research to be conducted. Thus, rather than relying solely on the intuition of individual practitioners (which, unfortunately, is all too often wrong), the empirical conclusions reached in this article suggest that interventions emphasizing norms and perceived behavioral control alone could be less effective than programs that attempt to change perceptions of the outcomes of condom use. Our findings suggest that changing attitudes will produce greater strides in stemming the current HIV pandemic.

\section{References}

References marked with an asterisk indicate studies included in the meta-analysis.

*Adler, N. E., Kegeles, S. M., Irwin, C. E., \& Wibbelsman, C. (1990). Adolescent contraceptive behavior: An assessment of decision processes. Journal of Pediatrics, 116, 463-471.

*Agnew, C. R. (1995, October). Expanding the principle of correspondence: Predicting condom-relevant behaviors. Paper presented at the joint meeting of the European Association of Experimental Social Psychology and the Society for Experimental Social Psychology, Washington, DC.

Ajzen, I. (1985). From intentions to actions: A theory of planned behavior. In J. Kuhl \& J. Beckman (Eds.), Action control: From cognition to behavior (pp. 11-39). New York: Springer-Verlag.

Ajzen, I. (1988). Attitudes, personality and behavior. Chicago: Dorsey.

Ajzen, I. (1991). The theory of planned behavior. Organizational Behavior and Human Decision Processes, 50, 179-211.

Ajzen, I., \& Driver, B. L. (1991). Prediction of leisure participation from behavioral, normative and control beliefs: An application of the theory of planned behavior. Leisure Studies, 13, 185-204.

Ajzen, I., \& Fishbein, M. (1973). Attitudinal and normative variables as predictors of specific behaviors. Journal of Personality and Social Psychology, 27, 41-57.

Ajzen, I., \& Fishbein, M. (1977). Attitude-behavior relations: A theoretical analysis and review of empirical research. Psychological Bulletin, $84,888-918$.

Ajzen, I., \& Fishbein, M. (1980). Understanding attitudes and predicting social behavior: Attitudes, intentions, and perceived behavioral control. Englewood Cliffs, NJ: Prentice Hall.

Ajzen, I., \& Fishbein, M. (in press). Attitudes and the attitude-behavior relation: Reasoned and automatic processes. In W. Stroebe \& M. Hewstone (Eds.), European review of social psychology. New York: Wiley.

Ajzen, I., \& Madden, T. J. (1986). Prediction of goal-directed behavior: Attitudes, intentions and perceived behavioral control. Journal of Experimental Social Psychology, 42, 426-435.

*Albarracín, D. (1996). Interactive themes and sources in condom-use messages: An analysis of alternative persuasion strategies. Manuscript submitted for publication.

Albarracín, D., \& Fishbein, M. (1993). Reasoned action and planned behavior: Annotated bibliography on empirical papers. Unpublished manuscript, University of Illinois at Urbana-Champaign.

*Albarracín, D., Fishbein, M., \& Middlestadt, S. (1998). Generalizing behavioral findings across times and measures: A study of condom use. Journal of Applied Social Psychology, 28, 657-674.

Albarracín, D., \& Wyer, R. S. (2000). The cognitive impact of past behavior. Influences on beliefs, attitudes and future behavioral decisions. Journal of Personality and Social Psychology, 79, 5-22.

Albarracín, D., \& Wyer, R. S. (in press). Elaborative and nonelaborative processing of a behavior-related communication. Personality and Social Psychology Bulletin.

Bandura, A. (1977). Analysis of self-efficacy theory of behavioral change. Cognitive Therapy and Research, 1, 287-308.

Bandura, A. (1986). Social foundations of thought and action: A social cognitive theory. Englewood Cliffs, NJ: Prentice Hall.

Bandura, A. (1989). Perceived self-efficacy in the exercise of personal agency. Bulletin of the British Psychological Society, 10, 411-424.

Bandura, A. (1992). Social foundations of thought and action: $A$ social cognitive theory. Englewood Cliffs, NJ: Prentice Hall.

Bandura, A. (1997). Self-efficacy: The exercise of control. New York: Freeman. 
Bargh, J. A. (1997). The automaticity of everyday life. In R. S. Wyer (Ed.), Advances in social cognition (Vol. 10, pp. 1-62). Mahwah, NJ: Erlbaum.

Bargh, J. A., Chaiken, S., Govender, R., \& Pratto, F. (1992). The generality of the automatic attitude activation effect. Journal of Personality and Social Psychology, 62, 893-912.

Bargh, J. A., Chen, C., \& Burrows, L. (1996). Automaticity of social behavior: Direct effects of trait construct and stereotype activation on action. Journal of Personality and Social Psychology, 71, 230-244.

*Basen-Enquist, K., \& Parcel, G. S. (1992). Attitudes, norms and selfefficacy: A model of adolescents' HIV related sexual risk behavior. Health Education Quarterly, 19, 263-274.

Becker, M. H. (1974). The health belief model and personal health behavior. Health Education Monographs, 2, 324-508.

Bem, D. J. (1965). An experimental analysis of self-persuasion. Journal of Experimental Social Psychology, 1, 199-218.

Bentler, P. M., \& Speckart, G. (1979). Models of attitude-behavior relations. Psychological Review, 86, 452-464.

Bentler, P. M., \& Wu, E. J. C. (1995). EQS structural equations program manual. Encino, CA: Multivariate Software.

Bollen, K. A. (1989). Structural equations with latent variables. New York: Wiley.

*Boyd, B., \& Wandersman, A. (1991). Predicting undergraduate condom use with the Fishbein and Ajzen and the Triandis attitude-behavior models: Implications for public health interventions. Journal of Applied Social Psychology, 21, 1810-1830.

*Breakwell, G. M., Millward, L. J., \& Fife-Schaw, C. (1994). Commitment to safer sex as a predictor of condom use among 16-20-year-olds. Journal of Applied Social Psychology, 24, 189-217.

Bryan, A. D., Aiken, L. S., \& West, S. G. (1996). Increasing condom use: Evaluation of a theory-based intervention to prevent sexually transmitted diseases in young women. Health Psychology, 15, 371-382.

Centers for Disease Control. (1993a). Baseline female questionnaire. Project RESPECT. Annotated. Atlanta, GA: Project RESPECT Group. *Centers for Disease Control. (1993b). Community Demonstration Projects (CSI data). Atlanta, GA: Community Demonstration Projects.

Centers for Disease Control. (1993c). Project RESPECT observation and feedback guide. Atlanta, GA: Project RESPECT group.

*Centers for Disease Control. (1996). Analyses of baseline data. Atlanta, GA: Project RESPECT Group.

Centers for Disease Control. (1997). Project RESPECT: Preliminary outcome study. Atlanta, GA: Project RESPECT Group.

*Chan, D. K. S., \& Fishbein, M. (1993). Determinants of college women's intentions to tell their partners to use condoms. Journal of Applied Social Psychology, 23, 1455-1470.

*Chan, D. K. (1994). Integrative theory of behavior. Unpublished doctoral dissertation, University of Illinois at Urbana-Champaign.

Coates, T. J., Soskolne, C. L., Calzavara, L. M., Read, S. E., Fanning, M. M., Shephard, F. A., Klein, M. M., \& Johnson, J. K. (1986). The reliability of sexual histories in AIDS-related research: Evaluation of an interview-administered questionnaire. Canadian Journal of Public Health, 778, 343-348.

${ }^{*}$ Cohen, J. (1988). Statistical power analysis for the behavioral sciences (2nd ed.). Hillsdale, NJ: Erlbaum.

*Cohen, J. B., Severy, L. J., \& Athola, O. T. (1978). An extended expectancy-value approach to contraceptive alternatives. Journal of Population, I, 22-41.

*Corby, N. H., Schneider-Jamner, M., \& Welwitschia, R. J. (1996). Using the theory of planned behavior to predict intention to use condoms among male and female injecting drug users. Joumal of Applied Social Psychology, 26, 52-75.

*Doll, J., \& Orth, B. (1993). The Fishbein and Ajzen theory of reasoned action applied to contraceptive behavior: Model variants and meaningfulness. Journal of Applied Social Psychology, 23, 395-415.
Eagly, A. H., \& Chaiken, S. (1993). The psychology of attitudes. Orlando, FL: Harcourt Brace.

Fazio, R. H. (1986). How do attitudes guide behavior? In R. M. Sorrentino \& E. T. Higgins (Eds.), Handbook of motivation and cognition: Foundations of social behavior (pp. 204-243). New York: Guilford Press.

Fazio, R. H. (1990). Multiple processes by which attitudes guide behavior: The MODE model as an integrative framework. In M. P. Zanna (Ed.), Advances in experimental social psychology (Vol. 23, pp. 74-97). Newbury Park, CA: Sage.

Fishbein, M. (1980). A theory of reasoned action: Some applications and implications. In H. E. Howe Jr. \& M. M. Page (Eds.), Nebraska Symposium on Motivation, 1979 (Vol. 27, pp. 65-116). Lincoln: University of Nebraska Press.

Fishbein, M., \& Ajzen, A. (1975). Beliefs, attitudes, intentions, and behavior: An introduction to theory and research. Reading, MA: AddisonWesley.

Fishbein, M., Bandura, A., Triandis, H. C., Kanfer, F. H., Becker, M. H., \& Middlestadt, S. E. (1992). Factors influencing behavior and behavior change (Report prepared for the National Institute of Mental Health). Bethesda, MD: National Institute of Mental Health.

Fishbein, M., \& Middlestadt, S. E. (1995). Noncognitive effects on attitude formation and change: Fact or artifact? Journal of Consumer Psychology; 4, 181-202.

*Fishbein, M., Trafimow, D., Middlestadt, S. E., Helquist, M., Francis, C., \& Eustace, M. A. (1995). Using a KAPB survey to identify determinants of condom use among sexually active adults from St. Vincent and the Grenadines. Journal of Applied Social Psychology, 25, 1-20.

Fisher, J. D., \& Fisher, W. A. (1992). Changing AIDS risk behavior. Psychological Bulletin, 111, 455-474.

Fisher, J. D., Fisher, W. A., Williams, S. S., \& Malloy, T. E. (1994). Empirical tests of an information-motivation-behavioral skills model of AIDS-preventive behavior with gay men and heterosexual university students. Health Psychology, 13, 238-250.

*Fisher, W. A. (1984). Predicting contraceptive behaviors among university men: The role of emotions and behavioral intentions. Journal of Applied Social Psychology, 2, 104-123.

*Fisher, W. A., Fisher, J. D., \& Rye, B. J. (1995). Understanding and promoting AIDS-preventive behavior: Insights from the theory of reasoned action. Health Psychology, 14, 255-264.

Forsyth, A. D., Carey, M. P., \& Fuqua, R. W. (1997). Evaluation of the validity of the condom-use self-efficacy scale (CUSES) in young men using two behavioral simulations. Health Psychology, 16, 175-178.

${ }^{*}$ Gallois, C., Terry, D., Timmins, P., Kashima, Y., \& McCamish, M. (1994). Safe sexual intentions and behavior among heterosexual and homosexual men: Testing the theory of correct reasoned action. Psychology and Health, 10, 1-16.

Gerrard, M., Gibbons, F. X., \& Bushman, B. J. (1996). Relation between perceived vulnerability to HIV and precautionary sexual behavior. Psychological Bulletin, 119, 390-409.

Glasman, L., \& Albarracín, D. (1995). Counseling and testing intervention for people at risk for heterosexual transmission of HIV. Unpublished manuscript.

Hedges, L. V., \& Olkin, I. (1985). Statistical methods for meta-analysis. Orlando, FL: Academic Press.

Herr, P. M. (1995). Whither fact, artifact and attitude: Reflections on the theory of reasoned action. Journal of Consumer Psychology, 4, 371-380.

Hu, L., \& Bentler, P. M. (1998). Fit indices in covariance structure modeling: Sensitivity to underparameterized model specification. Psychological Methods, 3, 424-453.

Jaccard, J., \& Wan-Choi, K. (1995). A paradigm for studying the accuracy of self-reports of risk behavior relevant to AIDS: Empirical perspectives on stability, recall basis, and transitory influences. Journal of Applied Social Psychology, 25, 1831-1858.

*Jemmott, L. S., \& Jemmott, J. B. (1991). Applying the theory of reasoned 
action to AIDS risk behavior: Condom use among Black women. Nursing Research, 40, 228-234.

Johnson, B. T. (1993). DSTAT 1. 10: Software for the meta-analytic review of research literatures. Hillsdale, $\mathrm{NJ}$ : Erlbaum.

Johnson, B. T., \& Eagly, A. H. (2000). Quantitative synthesis of social psychological research. In H. T. Reis \& C. M. Judd (Eds.), Handbook of research methods in social psychology (pp. 496-528). London: Cambridge University Press.

Kalichman, S. C., Carey, M. P., \& Johnson, B. T. (1996). Prevention of sexually transmitted HIV infection: A meta-analytic review of the behavioral outcome literature. Annals of Behavioral Medicine, 18, 6-15.

Kamb, M. L., Dillon, B. A., Fishbein, M., Willis, K. L., \& Project RESPECT Study Group. (1996). Quality assurance of HIV prevention counseling in a multi-center randomized controlled trial. Public Health Reports, 111, 99-107.

Kamb, M. L., Fishbein, M., Douglas, J., Jr., Rhodes, F., Rogers, J., Bolan, G., Zenilman, J., Hoxworth, T., Malotte, K., Iatesta, M., Kent, C., Lentz, A., Graziano, S., Byers, R., Peterman, T., \& the Project RESPECT Study Group. (1998). HIV prevention counseling for high risk behaviors: Results from a randomized controlled trial (Project RESPECT). Journal of the American Medical Association, 280, 1161-1167.

*Kashima, Y., Gallois, C., \& McCamish, M. (1993). The theory of reasoned action and cooperative behaviour: It takes two to use a condom. British Journal of Social Psychology, 32, 227-239.

Kelly, J. A., Murphy, D., Sikkema, K. J., \& Kalichman, S. C. (1993). Psychological interventions to prevent HIV infection are urgently needed: New priorities for behavioral research in the second decade of AIDS. American Psychologist, 48, 1023-1034.

Kelly, J. A., Murphy, D. A., Washington, C. D., Wilson, T. S., Koob, J. J., Davis, D. R., Ledezma, G., \& Davantes, B. (1994). The effects of HIV/AIDS intervention groups for high-risk women in urban clinics. American Journal of Public Health, 84, 1918-1922.

*Lavoie, M., \& Godin, G. (1991). Correlates of intention to use condoms among auto mechanic students. Health Education Research, 6, 313-316.

*McCarty, D. (1981). Changing contraceptive usage intentions: A test of the Fishbein model of intention. Journal of Applied Social Psychology, 11, 192-211.

McLaws, M., Oldenbrug, B., Ross, M. W., \& Cooper, D. A. (1990). Sexual behavior in AIDS-related research: Reliability and validity of recall and diary measures. Journal of Sex Research, 27, 265-281.

Middlestadt, S. E., Fishbein, M., Albarracín, D., \& Helquist, M. (1995), Evaluating the impact of a National AIDS Prevention Radio Campaign in St. Vincent and the Grenadines. Journal of Applied Social Psychology, 25, 21-34.

*Montaño, D. E., Kazprzyk, D., \& Fishbein, M. (1996). Application of an integrated behavioral model to change condom use behaviors. Unpublished manuscript.

*Morrison, D. M., Gillmore, M. R., \& Baker, S. A. (1995). Determinants of condom use among high-risk heterosexual adults: A test of the theory of reasoned action. Journal of Applied Social Psychology, 25, 651-676.

*Nucifora, J., Gallois, C., \& Kashima, Y. (1993). Influences on condom use among undergraduates: Testing the theories of reasoned action and planned behaviour. In D. J. Terry, C. Gallois, \& M. McCamish (Eds.), The theory of reasoned action: Its application to AIDS-preventive behaviour (pp. 47-64). Oxford, England: Penguin.

Osberg, T. M., \& Shrauger, J. S. (1986). Retrospective versus prospective judgments of self and others' behavior. Journal of Social Psychology, 126, 169-178.

Ouellette, J. A., \& Wood, W. (1998). Habit and intention in everyday life: The multiple processes by which past behavior predicts future behavior. Psychological Bulletin, 124, 54-74.

*Pendergrast, R. A., DuRant, R. H., \& Gaillard, G. L. (1992). Attitudinal and behavioral correlates of condom use in urban adolescent males. Journal of Adolescent Health, 13, 133-139.
Premack, S. L., \& Hunter, J. E. (1988). Individual unionization decisions. Psychological Bulletin, 103, 223-234.

*Reinecke, J., Schmidt, P., \& Ajzen, I. (1996). Application of the theory of reasoned action to adolescents' condom use: A panel study. Journal of Applied Social Psychology, 26, 749-772.

Reis, J., Fishbein, M., \& Moore, L. (1996, November). Interactive multimedia software for promotion of condom use among African American adolescents. Paper presented at the meeting of the American Public Health Association, New York.

*Richard, R., Van der Plight, J., \& de Vries, N. (1995). Anticipated affective reaction and prevention of AIDS. British Journal of Social Psychology, 34, 9-21.

*Rigby, K., Dietz, B., \& Sturgess, S. (1993). The theory of reasoned action as applied to AIDS prevention for Australian ethnic groups. In D. J. Terry, C. Gallois, \& M. McCamish (Eds.), The theory of reasoned action: Its application to AIDS-preventive behaviour (pp. 93-115). Oxford, England: Penguin.

*Rise, J. (1992). An empirical study of the decision to use condoms among Norwegian adolescents using the theory of reasoned action. Journal of Community and Applied Social Psychology, 2, 185-197.

Rosenstock, I. M. (1974). Historical origins of the health belief model. Health Education Monographs, 2, 1-8.

Ross, M. (1989). Relation of implicit theories to the construction of personal histories. Psychological Review, 96, 341-357.

*Ross, M. W., \& McLaws, M. L. (1992). Subjective norms about condoms are better predictors of use and intentions to use than attitudes. Health Education Research, 7, 335-339.

Rotter, J. B. (1954). Social learning and clinical psychology. New York: Prentice Hall.

*Rye, B. J. (1996). The theory of reasoned action and the theory of planned behavior in relation to university women's safer sex behaviors: A prospective investigation. Unpublished doctoral dissertation, University of Western Ontario, London, Ontario, Canada.

*Schaalma, H., Kok, G., \& Peters, L. (1993). Determinants of consistent condom use by adolescents: The impact of experience of sexual intercourse. Health Education Research, 8, 255-269.

Schifter, D. E., \& Ajzen, I. (1985). Intention, perceived behavioral control and weight loss: An application of the theory of planned behavior. Journal of Personality and Social Psychology, 49, 843-851.

Shadish, W. R. (1996). Meta-analysis and the exploration of causal mediating processes: A primer of examples, methods and issues. Psychological Methods, 1, 47-65.

Sheeran, P., \& Orbell, S. (1998). Do intentions predict condom use? Meta-analysis and examination of six moderator variables. British Journal of Social Psychology, 37, 231-250.

Sheppard, B. H., Hartwick, J., \& Warshaw, P. R. (1988). The theory of reasoned action: A meta-analysis of past research with recommendations for modifications and future research. Journal of Consumer Research, $15,325-343$.

Strack, F. (1995). Response processes in social judgment. In R. S. Wyer \& T. K. Srull (Eds.), Handbook of social cognition (Vol. 1, pp. 287-322). Hillsdale, NJ: Erlbaum.

*Tashakkori, A., \& Thompson, V. D. (1990, August). Predictors of intention to take precautions against AIDS among Black college students. Paper presented at the 98th Annual Convention of the American Psychological Association, Boston, MA.

*Terry, D. J. (1993). Self-efficacy expectancies and the theory of reasoned action. In D. J. Terry, C. Gallois, \& M. McCamish (Eds.), The theory of reasoned action: Its application to AIDS-preventive behaviour (pp. 135-151). Oxford, England: Penguin.

*Trafimow, D. (1994). Predicting intentions to use a condom from the perceptions of normative pressure and confidence in those perceptions. Journal of Applied Social Psychology, 24, 2151-2163.

van den Putte, B. (1991). 20 years of the theory of reasoned action of 
Fishbein and Ajzen: A meta-analysis. Unpublished manuscript, University of Amsterdam, Amsterdam, the Netherlands.

Viewesvaran, C., \& Ones, D. S. (1995). Theory testing: Combining psychometric data and structural equation modeling. Personnel Psychology, 48, 865-886.

*Warwick, P., Terry, D., \& Gallois, C. (1993). Extending the theory of reasoned action: The role of health beliefs. In D. J. Terry, C. Gallois, \& M. McCamish (Eds.), The theory of reasoned action: Its application to AIDS-preventive behaviour (pp. 117-133). Oxford, England: Penguin.

Weinhardt, L. S., Carey, M. P., Johnson, B. T., \& Bickham, N. (1999). Effects of HIV counseling and testing on sexual risk behavior: Metaanalytic review of published research, 1985-1997. American Journal of Public Health, 89, 1397-1405.

West, S. G., \& Aiken, L. S. (1997). Toward understanding individual effects in multicomponent prevention programs: Design and analysis strategies. In K. J. Bryant \& M. Windle (Eds.), The science of prevention: Methodological advances from alcohol and substance abuse research (pp. 167-209). Washington, DC: American Psychological Association.

*Westaby, J. D., \& Fishbein, M. (1993). Reasons theory as a new parsimo- nious predictor of intentions and behavior: Implications for behavioral explanution and change. Unpublished manuscript, University of Illinois.

"White, K. M., Terry, D. J., \& Hogg, M. A. (1994). Safer sex behavior: The role of attitudes, norms and control factors. Journal of Applied Social Psychology, 24, 2164-2192.

*Wilson, D., Zenda, A., McMaster, J., \& Lavelle, S. (1992). Factors predicting Zimbawean students' intentions to use condoms. Psychology and Health, 7, 99-114.

Winkelstein, W., Samuel, M., Padian, N., Wiley, J., Lang, W., Anderson, R., \& Levy, J. (1987). The San Francisco men's health study: III. Reduction in HIV transmission among homosexual/bisexual men, 19821986. American Journal of Public Health, 76, 685-689.

Wyer, R. S., \& Srull, T. K. (1989). Memory and cognition in its social context. Hillsdale, NJ: Erlbaum.

Received March 18, 1998

Revision received April 16, 2000

Accepted May 4, 2000

\section{New Editors Appointed, 2002-2007}

The Publications and Communications Board of the American Psychological Association announces the appointment of five new editors for 6-year terms beginning in 2002.

As of January 1,2001, manuscripts should be directed as follows:

- For Behavioral Neuroscience, submit manuscripts to John F. Disterhoft, PhD, Department of Cell and Molecular Biology, Northwestern University Medical School, $303 \mathrm{E}$. Chicago Avenue, Chicago, IL 60611-3008.

- For the Journal of Experimental Psychology: Applied, submit manuscripts to Phillip L. Ackerman, PhD, Georgia Institute of Technology, School of Psychology, MC 0170, 274 5th Street, Atlanta, GA 30332-0170.

- For the Journal of Experimental Psychology: General, submit manuscripts to D. Stephen Lindsay, PhD, Department of Psychology, University of Victoria, P.O. Box 3050, Victoria, British Columbia, Canada V8W 3P5.

- For Neuropsychology, submit manuscripts to James T. Becker, PhD, Neuropsychology Research Program, 3501 Forbes Avenue, Suite 830, Pittsburgh, PA 15213.

- For Psychological Methods, submit manuscripts to Stephen G. West, PhD, Department of Psychology, Arizona State University, Tempe, AZ 85287-1104.

Manuscript submission patterns make the precise date of completion of the 2001 volumes uncertain. Current editors, Michela Gallagher, PhD; Raymond S. Nickerson, PhD; Nora S. Newcombe, $\mathrm{PhD}$; Patricia B. Sutker, $\mathrm{PhD}$; and Mark I. Appelbaum, $\mathrm{PhD}$, respectively, will receive and consider manuscripts through December 31, 2000. Should 2001 volumes be completed before that date, manuscripts will be redirected to the new editors for consideration in 2002 volumes. 